\title{
Pleiotropic Functions for Transcription Factor Zscan10
}

\author{
Petra Kraus ${ }^{1,2}$, Sivakamasundari $\mathrm{V}^{1}$, Hong Bing $\mathrm{Yu}^{1}{ }^{1}$, Xing $\mathrm{Xing}^{1}$, Siew Lan Lim ${ }^{1}$, Thure Adler ${ }^{3,4}$, Juan \\ Antonio Aguilar Pimentel ${ }^{3,4,12}$, Lore Becker ${ }^{3,4}$, Alexander Bohla ${ }^{3,13}$, Lillian Garrett ${ }^{3,5}$, Wolfgang Hans ${ }^{3,4}$, \\ Sabine M. Hölter ${ }^{3,5}$, Eva Janas ${ }^{3,6}$, Kristin Moreth ${ }^{3,4}$, Cornelia Prehn ${ }^{3,4}$, Oliver Puk ${ }^{3,5}$, Birgit Rathkolb ${ }^{3,7}$, \\ Jan Rozman ${ }^{3,4}$, Jerzy Adamski ${ }^{3,4}$, Raffi Bekeredjian ${ }^{3,8}$, Dirk H. Busch ${ }^{3,9}$, Jochen Graw ${ }^{3,5}$, \\ Martin Klingenspor ${ }^{3,10}$, Thomas Klopstock ${ }^{3,11}$, Frauke Neff ${ }^{3,6}$, Markus Ollert ${ }^{3,12}$, Tobias Stoeger ${ }^{3,13}$, Ali \\ Önder Yildrim ${ }^{3,13}$, Oliver Eickelberg ${ }^{3,13}$, Eckhard Wolf ${ }^{3,7}$, Wolfgang Wurst ${ }^{3,5,16,17,18,19}$, Helmut Fuchs ${ }^{3,4}$, \\ Valérie Gailus-Durner ${ }^{3,4}$, Martin Hrabě de Angelis ${ }^{3,4,14,15}$, Thomas Lufkin ${ }^{1,2}$, Lawrence W. Stanton ${ }^{1 *}$ \\ 1 Stem Cell and Developmental Biology, Genome Institute of Singapore, Singapore, Singapore, 2 Department of Biology, Clarkson University, Potsdam, New York, United \\ States of America, $\mathbf{3}$ German Mouse Clinic, Helmholtz Zentrum München, German Research Center for Environmental Health, Neuherberg, Germany, $\mathbf{4}$ Institute of \\ Experimental Genetics, Helmholtz Zentrum München, German Research Center for Environmental Health, Neuherberg, Germany, $\mathbf{5}$ Institute of Developmental Genetics, \\ Helmholtz Zentrum München, German Research Center for Environmental Health, Neuherberg, Germany, $\mathbf{6}$ Institute of Pathology, Helmholtz Zentrum München, German \\ Research Center for Environmental Health, Neuherberg, Germany, $\mathbf{7}$ Chair for Molecular Animal Breeding and Biotechnology, Gene Center, Ludwig-Maximilians-Universität \\ München, Munich, Germany, 8 Department of Medicine III, Division of Cardiology, University of Heidelberg, Heidelberg, Germany, 9 Institute of Medical Microbiology, \\ Immunology, and Hygiene, Technische Universität München, Munich, Germany, 10 Molecular Nutritional Medicine, Else Kröner-Fresenius Center, Technische Universität \\ München, Freising-Weihenstephan, Germany, 11 Department of Neurology, Friedrich-Baur-Institut, Ludwig-Maximilians-Universität München, Munich, Germany, \\ 12 Klinikum rechts der Isar der Technischen Universität München, Klinik und Poliklinik für Dermatologie und Allergologie am Biederstein, Munich, Germany, \\ 13 Comprehensive Pneumology Center, Institute of Lung Biology and Disease, Helmholtz Zentrum München, German Research Center for Environmental Health, \\ Neuherberg, Germany, 14 Chair of Experimental Genetics, Center of Life and Food Sciences Weihenstephan, Technische Universität München, Freising-Weihenstephan, \\ Germany, 15 Member of German Center for Diabetes Research, Neuherberg, Germany, $\mathbf{1 6}$ Chair of Developmental Biology, Technische Universität München, Freising- \\ Weihenstephan, Germany, 17 Max Planck Institute of Psychiatry, Munich, Germany, 18 Deutsches Institut für Neurodegenerative Erkrankungen Site Munich, Munich, \\ Germany, 19 Munich Cluster for Systems Neurology, Munich, Germany
}

\section{Abstract}

The transcription factor Zscan10 had been attributed a role as a pluripotency factor in embryonic stem cells based on its interaction with Oct4 and Sox2 in in vitro assays. Here we suggest a potential role of Zscan10 in controlling progenitor cell populations in vivo. Mice homozygous for a Zscan10 mutation exhibit reduced weight, mild hypoplasia in the spleen, heart and long bones and phenocopy an eye malformation previously described for Sox2 hypomorphs. Phenotypic abnormalities are supported by the nature of Zscan10 expression in midgestation embryos and adults suggesting a role for Zscan10 in either maintaining progenitor cell subpopulation or impacting on fate choice decisions thereof.

Citation: Kraus P, V S, Yu HB, Xing X, Lim SL, et al. (2014) Pleiotropic Functions for Transcription Factor Zscan10. PLoS ONE 9(8): e104568. doi:10.1371/journal. pone. 0104568

Editor: Shree Ram Singh, National Cancer Institute, United States of America

Received April 24, 2014; Accepted July 12, 2014; Published August 11, 2014

Copyright: (c) 2014 Kraus et al. This is an open-access article distributed under the terms of the Creative Commons Attribution License, which permits unrestricted use, distribution, and reproduction in any medium, provided the original author and source are credited.

Data Availability: The authors confirm that all data underlying the findings are fully available without restriction. All relevant data are within the paper and its Supporting Information files.

Funding: This work was supported by the Agency for Science Technology and Research (A*STAR) Singapore. GMC researchers were funded by the German Federal Ministry of Education and Research (Infrafrontier grant 01KX1012), the German Center for Diabetes Research (DZD), the German Center for Vertigo and Balance Disorders (grant 01EO 0901), and by the Helmholtz Alliance for Mental Health in Ageing Society (HA-215). The funders had no role in study design, data collection and analysis, decision to publish, or preparation of the manuscript.

Competing Interests: One or more of the authors are employed by a commercial company (German Mouse Clinic, Helmholtz Zentrum München, German Research Center for Environmental Health $(\mathrm{GmbH})$ ). The affiliation(s) to this company, along with any other relevant declarations relating to employment, consultancy, patents, products in development or marketed products etc. does not alter our adherence to PLOS ONE policies on sharing data and materials.

*Email: stantonl@gis.a-star.edu.sg

\section{Introduction}

Zscan10 (previously known as Zfp206) is a 14 zinc finger transcription factor (ZF-TF) of the $\mathrm{C}_{2} \mathrm{H}_{2} \mathrm{ZF}-\mathrm{TF}$ subfamily with a N-terminal SGAN domain [1,2] located on mouse chromosome 17. It was discovered during an array screen in mouse [3] and a transcriptome characterization of human embryonic stem cells [4]. Zscan10 has at least six known alternative splice forms, is expressed in undifferentiated human and mouse embryonic stem cells (ESC) $[3,4]$, the inner cell mass (ICM) of blastocysts [5] and down regulated upon differentiation $[3,6]$. Zscan10 is considered to maintain ESC pluripotency by interacting with the established pluripotency markers Sox 2 and Oct4 [7]. More than 3000 binding sites were identified for Zscan 10 in a genome wide screen of which 183 were commonly targeted by this trio [1]; suggesting a direct or indirect role of Zscan10 in controlling many developmental processes by activating or suppressing other transcription factors. Post-implantation expression of the Zscan10 isoform 2 has been reported by whole mount RNA in situ hybridization (WISH) in the ecto- and mesoderm but not the endoderm of embryonic day 7.5 (E7.5) mouse embryos. Expression remained in the otic vesicle, the branchial arches and the hindgut between E9.0-9.5 and 
became barely detectable at E10.5 [3], while WISH using a probe based on the last exon of Zscan 10 indicated expression in the ectoderm and mesoderm but not endoderm of E7.5 embryos and low level expression in all germ layers from E9.5 to E12.5. Northern blot analysis performed with a 60 bp oligonucleotide located in the last exon of Zscan 10 revealed strongest expression in embryos at E4.5-E5.5 and E10.5-E13.5, while in the adult expression was limited to the testis [6]. Subsequently qPCR analysis indicated low level expression in brain and liver. Array data from Zhang et al. indicated upregulation of Zscan10 expression in E9.5 embryos as well as lymph nodes, the spinal cord, testis and epididymis as well as femur and calvarial bones [3]. While the last exon is present in the most abundant isoforms of Zscan 10, only exon 4 is shared amongst all six known alternative splice variants [3].

During post-fertilization pre-implantation stages in mouse, a totipotent zygote develops into a pluripotent blastocyst by E3.5 with only the cells of the ICM retaining the pluripotent state. Pluripotent ESG can be derived from the ICM of blastocysts $[8,9]$. Upon injection of pluripotent ESG into $2 \mathrm{C}-8 \mathrm{C}$ stage preimplantation embryos [10] or blastocysts [11] chimeric organisms can be generated. The degree of chimerism is determined by the degree of pluripotency of any given injected ESC and its ability to outcompete cells of the host organism to achieve contribution to the chimeric organism and from an evolutionary point of view, most importantly its germ line [10]. Upon undergoing differentiation, a pluripotent stem cell can divide into a terminally differentiated cell or become a more specialized progenitor cell with multi- or unipotent potential [12].

Here we propose a possible role for Zscan 10 in the maintenance of multipotent progenitor cells based on the pleiotropic phenotype revealed by an exhaustive screen of Zscan 10 homozygous mutant mice derived from clone \#285B6 (CMMR) of a gene trap located $5^{\prime}$ to the ATG start codon of Zscan10, which should render null all known protein isoforms of Zscan10, yet allow residual 3' RNA expression to persist. Typically affected organs did retain residual Zscan10 RNA expression in distinct cells during midgestation development and even in the adult and were generally determined to be hypoplastic in the Zscan10 homozygous mutants.

\section{Materials and Methods}

\section{Generation of homozygous mutant Zscan10 gene trap mice}

Zscan10 mutant mice were generated by injecting the $\mathrm{R} 1$ mouse ESC clone \#285B6, obtained from the Canadian Mouse Mutant Repository (CMMR) (Toronto, Canada), into C57BL/6 2C-8C stage embryos as described in Kraus et al. [10], achieving germline transmission and generating a stable line that was backcrossed for more than three generations onto a C57BL/6 background. According to CMMR clone \#285B6 resulted from a gene trap insertion of the pUPA vector prior to the translation start codon of Zscan10 as confirmed by 3'RACE performed by CMMR. For a schematic of the gene trap allele see Figure S1. As recommended by CMMR, heterozygous mice were mated with the ZP3-Cre deleter strain [13] to remove a floxed IRESx3 sequence inherent to the pUPA gene trap vector used by CMMR. Genotyping was performed by PCR using the AccuPrime Taq DNA polymerase system on $50 \mathrm{ng}$ of genomic DNA isolated from tail tips for 30 cycles at $94^{\circ} \mathrm{C}$ for $30 \mathrm{~s} / 58^{\circ} \mathrm{C}$ for $30 \mathrm{~s} / 68^{\circ} \mathrm{C}$ for $60 \mathrm{~s}$ with primers for the mutant (285B6-mut-F: 5'-CGATGATCTCGTCGTGACCC-3' / 285B6-mut-R: 5'-CGGGTCAAATTACGAGGTGCT-3') and wild type allele (285B6-wt-F: 5'-CTGGCAAGTCGTCACGTAGAAATT-3' / 285B6-wt-R: 5'-CTGGAG-
CAGATGCTCGTGAGTT-3'), generating a 300 bp wild type allele and a $1100 \mathrm{bp}$ and $500 \mathrm{bp}$ mutant allele before and after Cre recombination, respectively.

\section{Ethics statement and animal housing}

All animal procedures were performed according to the Singapore A*STAR Biopolis Biological Resource Center (BRC) Institutional Animal Care and Use Committee (IACUC) guidelines which are set by the National Advisory Committee for Laboratory Animal Research (NACLAR). The IACUC protocols employed were reviewed and approved by the aforementioned committee before any animal procedures were undertaken for this study described here (IACUC Protocol No: 110689 and 110648). The mouse strains used in this study were housed, maintained and provided by the A*STAR Biopolis Biological Resource Center (BRC) (Singapore) \& the German Mouse Clinic (GMC) (Neuherberg, Germany) and maintained in IVC cages according to BRC and GMC housing conditions and Singaporean and German laws. All tests performed at the GMC and described here were approved for the ethical treatment of animals by the responsible authority of the Regierung von Oberbayern (Government of Upper Bavaria). The lines described here will be made available to the research community upon acceptance of the manuscript.

\section{RNA in situ hybridization and Western blot}

RNA in situ hybridization on 10 um paraffin sections (SISH) was carried out, essentially as described [14], with the exception that the probes were generated by PCR amplification of wild type mouse cDNA derived from embryonic E12.5 and R1 ESC, as described [15,16]. Several Zscan10 probes have been used for SISH, emphasized here is the 270 bp probe template that spans exons 3 to 5 of the Zscan10 cDNA, precisely from base pair position 667 to 937 of the reference sequence NM_001033425 and the 1355 bp probe template spanning base positions 433 to 1788 . PCR was carried out following standard PCR procedures using GoTaq (Promega) at $1.0 \mathrm{mM} \mathrm{MgCl} 2$ on a Nexus Eppendorf thermocycler with a $40 \mathrm{~s}$ annealing step at $65^{\circ} \mathrm{C}$ and $2.0 \mathrm{mM}$ $\mathrm{MgCl}_{2}$ at $60^{\circ} \mathrm{C}$, respectively, for 35 cycles with primers including the sequence for the T3 and T7 RNA polymerase promoters, to generate a DIG labeled sense and antisense probe, respectively, using the DIG RNA labeling mix (Roche):

Zfp206_T3: 5'-GGGGGGTTAATTGGGAGTGATTTCGGCCTCAGAAGAGATTCCAGCCA-3', Zfp206_T7: 5'-GGGCGCGTAATACGACTCACTATAGGGCGCCAAGCTCTCTTCTCTGAGGT-3', Zscan10_433_T3: 5'-CGGGGGCAATTAACGCTCACTAAAGGGCTGGAGCAGTTCCTGAGTGTC-3', Zscan10_1788_T7:5'-GGGGGCGTAATAGGACTCACTATAGGGCTAGTTGCTCGCTTTGTCGGAA-3'. Likewise a $\sim 1 \mathrm{~kb}$ probe for Sox2 was generated using the primers: T7_Sox2_S: 5'GCGGGCGTAATACGACTCACTATAGGGCTTTGTCGGAGACGGAGAAGG-3', T3_Sox2_AS: 5'- CGGGGGGAATTAACCCTCACTAAAGGGGAAGGGCGTAACGTACGACT3'. The ORF Hes 5 probe was a generous gift from Urban Lendahl. The probe template for the PUPA reporter gene EGFP was amplified using the primers EGFP_T7: 5'-CGGGCGCAATTAACCCTCACTAAAGGGCCTACGGCGTGCAGTGCTTCAGC-3' and EGFP_T3: 5:-CGGGGGGTAATAGGACTCACTATAGGGCGGGCGAGCTGCACGCTGCCGTCG-3' .

Western blot was essentially performed as described [6] with a Zscan10 specific antibody at 1:3000 and aRB-HRP $1: 10000$ as control (see Figure S5). For comparison wild type $(+/+)$, heterozygous $(+/-)$ and homozygous $(-/-)$ ESC were derived from blastocysts of $Z \operatorname{scan} 10^{+-} \times Z_{\text {scan } 10^{+/-}}$matings. The homozygous $(-/-)$ line L2 was maintained on gelatinized plates 
in the absence (GEL) or presence (MEF) of mouse embryonic fibroblast feeder cells all maintained in ES medium+LIF.

\section{Phenotype screen at GMC}

The GMC screen (www.mouseclinic.de) comprises exhaustive, standardized phenotyping in the realms of dysmorphology, cardiovascular health, energy metabolism, clinical chemistry, eye, lung function, molecular phenotyping, behavior, neurology, nociception, immunology, steroid metabolism and pathology. Phenotypic screens at the GMC were performed according to standardized methods $[17,18,19]$. A cohort of each 15 male and 15 female wild type and homozygous mutant adult mice derived from timed heterozygous $\mathrm{x}$ heterozygous matings, all born within one week, was subjected to the GMC phenotyping program between the age of 9 to 18 weeks. If not stated otherwise, data generated by the GMC was analyzed using R. Tests for genotype effects were made by using t-test, Wilcoxon rank sum test, linear models, or ANOVA depending on the assumed distribution of the parameter and the questions addressed to the data. A p-value $<$ 0.05 has been used as level of significance; a correction for multiple testing has not been performed.

\section{Dysmorphology and skeletal analysis}

Macroscopic examination to identify any morphological abnormalities was performed according to GMC standard operating procedures (SOP). Growth weight and body size was determined. Mice were subjected to morphological observation and hearing abilities were analyzed following the protocol described previously [20]. X-ray imaging of animals was performed in a Faxitron MX-20 Cabinet X-ray system equipped with a DC12 digital camera (Faxitron X-ray, Illinois, USA). The system is run with settings: Voltage $26 \mathrm{kV}$ and automatic exposure control. Bone mineral density was analyzed using pDEXA Sabre X-ray Bone Densiometer (Norland Medical Systems. Inc., Basingstoke, Hamshire, UK) scan speed $20 \mathrm{~mm} / \mathrm{s}$, resolution $0.5 \mathrm{~mm} \times 1.0 \mathrm{~mm}$, Histogram Averaging Width setting $0.020 \mathrm{~g} /$ $\mathrm{cm}^{2}$.

\section{Eye analysis and pathology}

Morphological alterations of the eye such as anterior segment abnormalities were assessed by Scheimpflug imaging, posterior segment abnormalities, eye fundus and retina were analyzed by optical coherence tomography. The axial eye length was measured by laser interference biometry [21] and visual properties were studied in tests involving a virtual drum [22]. For microscopic histological analysis all organs (skin, heart, muscle, lung, brain, cerebellum, thymus, spleen, cervical lymph nodes, thyroid, parathyroid, adrenal gland, stomach, intestine, liver, pancreas, kidney, reproductive organs and urinary bladder) were fixed in $4 \%$ buffered formalin, embedded in paraffin, sectioned at a thickness of $2 \mathrm{um}$ and subjected to hematoxylin and eosin staining as described before [19].

\section{Neurological examination and behavioral testing}

For the assessment of basic neurological functions, muscle function as well as motor coordination and balance, a modified SHIRPA protocol was applied and grip strength and Rota rod performance were measured as described previously [19]. Behavioral screens to analyze locomotion and anxiety-related behavior as well as sensory motor gaiting were done by open field (OFT), acoustic startle and prepulse inhibition (PPI) testing as described before $[23,24]$.

\section{Clinical chemistry, hematology and immunology assessment}

Blood samples were collected at 16 weeks of age by retrobulbar puncture under isoflurane anesthesia. Determination of clinicalchemical parameters in heparinized plasma samples was done using an AU480 (Beckman-Coulter, Krefeld, Germany) and reagents kits provided by Beckman-Coulter, as described previously [25]. Hematological analyses were performed with an ABCanimal blood counter (Scil animal care company, Viernheim, Germany) on whole blood samples collected in EDTA-coated tubes. Glucose tolerance was tested by an intraperitoneal glucose tolerance test (IpGTT) performed after overnight food withdrawal using the Accucheck Aviva glucometer (Roche, Penzberg, Germany) for glucose blood level determination, as described previously [26]. Analysis of peripheral blood samples was done by flow cytometry and Bioplex multiplex bead array [17,19].

\section{Heart and lung function screen}

Awake echo was used for the assessment of cardio-vascular functions [26] while assessment of lung volumes and mechanics was performed by Buxco FinePointeRG and Forced Maneuvers systems as described previously [19].

\section{Energy and steroid metabolism}

Measurement of body mass, body temperature, locomotor activity, $\mathrm{O}_{2}$ consumption, $\mathrm{CO}_{2}$ production, respiratory exchange ratio and body composition was assessed by indirect calorimetry and qNMR (MiniSpec LF50, Bruker Optics, Ettlingen/Germany). The steroid hormones testosterone, corticosterone and androstendione were analyzed out of $50 \mathrm{ul}$ plasma by liquid chromatography tandem mass spectrometry (LC-MS/MS) according to Rathkolb et al [25].

\section{Results}

\section{Underrepresentation of homozygous Zscan 10 mutant females at weaning age}

While homozygous Zscan10 mutants were viable and fertile, genotyping offspring $(n=153)$ from heterozygous $x$ heterozygous matings at weaning age (postnatal day 21) revealed a slight deviation from the expected Mendelian ratio, with the number of homozygous females being 30\% lower than that of wild type females (see Table S1). Notably, homozygous mice were fertile and could be maintained as homozygous $\mathrm{x}$ homozygous, yet their breeding performance generally dropped after a few litters and the offspring appeared increasingly runted (data not shown). Therefore, heterozygous $\mathrm{x}$ heterozygous matings were preferred to maintain the Zscan10 mutant mouse line. Zscan10 is known to have several alternative splice forms (see Figure S1). While the integration of the gene trap allele will not prevent residual RNA transcripts from being generated, it is very unlikely that any of the Zscan 10 protein isoforms are produced (see Figure S5).

\section{Decreased body weight, bone mass and bone mineral content in Zscan10 homozygous mutant females}

The body mass of the female mutant Zscan10 cohort was slightly, but significantly, $(\mathrm{p}=0.042)$ reduced (see Figure 1A-D); in male mutant mice a reduction was observed but did not reach a significant value. The relationship between body fat content and lean mass was not different between mutant and wild type mice, therefore no clear shift in body composition could be detected (see Figure 1D,E,G). In the dual-energy X-ray absorptiometry (DXA) a significantly decreased bone mineral content (BMC) and bone 
A

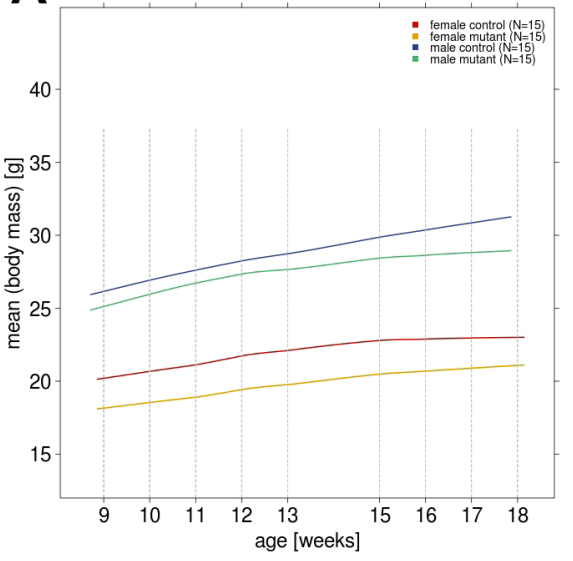

B

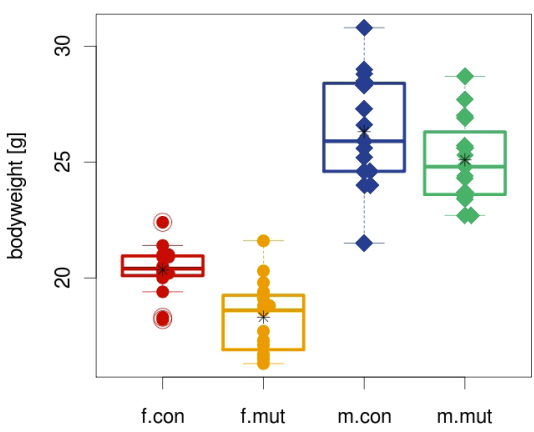

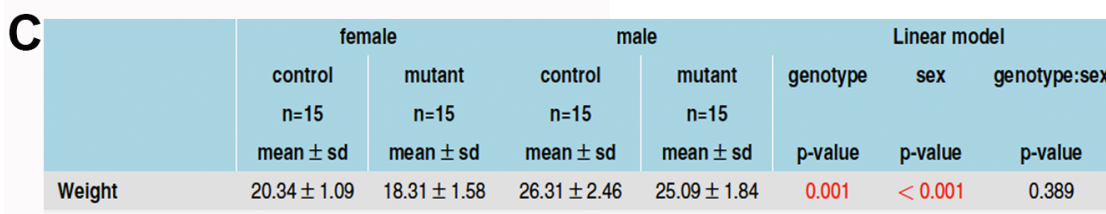

\begin{tabular}{|l|cccc|cccc|}
\hline & \multicolumn{2}{|c}{ female } & \multicolumn{2}{c}{ male } & \multicolumn{4}{c|}{ Linear model } \\
& control & mutant & control & mutant & sex & genotype & body mass & sex:genotype \\
\hline & $\mathrm{n}=15$ & $\mathrm{n}=15$ & $\mathrm{n}=15$ & $\mathrm{n}=15$ & & & & \\
\hline & mean $\pm \mathbf{s d}$ & mean $\pm \mathbf{s d}$ & mean $\pm \mathbf{s d}$ & mean $\pm \mathbf{s d}$ & $\mathrm{p}$-value & $\mathrm{p}$-value & $\mathrm{p}$-value & $\mathrm{p}$-value \\
\hline Body mass & $21.1 \pm 1.2$ & $18.8 \pm 1.4$ & $27.5 \pm 2.6$ & $26.6 \pm 2$ & $<0.001$ & 0.002 & $\mathrm{NA}$ & 0.167 \\
\hline Fat mass & $4.8 \pm 0.4$ & $4 \pm 0.5$ & $5.6 \pm 0.7$ & $5.2 \pm 0.7$ & $<0.001$ & 0.118 & $<0.001$ & 0.352 \\
\hline Lean mass & $13.3 \pm 0.7$ & $12.1 \pm 0.9$ & $18.3 \pm 1.6$ & $17.6 \pm 1.2$ & $<0.001$ & 0.658 & $<0.001$ & 0.12
\end{tabular}

\begin{tabular}{|c|c|c|c|c|c|c|c|c|c|}
\hline & mean \pm sd & mean $\pm s d$ & mean $\pm s d$ & mean $\pm s d$ & pairwise (Tukey) & pairwise (Tukey) & ANOVA & ANOVA & ANOVA \\
\hline & $\begin{array}{l}\text { female } \\
\text { control } \\
\mathrm{N}=15\end{array}$ & $\begin{array}{l}\text { female } \\
\text { mutant } \\
\mathrm{N}=13\end{array}$ & $\begin{array}{l}\text { male } \\
\text { control } \\
\mathrm{N}=14\end{array}$ & $\begin{array}{c}\text { male } \\
\text { mutant } \\
\mathrm{N}=13\end{array}$ & $\begin{array}{l}\text { females } \\
\text { mutant-control } \\
\text { adj. p-value }\end{array}$ & $\begin{array}{l}\text { males } \\
\text { mutant-control } \\
\text { adj. p-value }\end{array}$ & $\begin{array}{c}\text { genotype } \\
\text { p-value }\end{array}$ & $\begin{array}{l}\text { sex } \\
\text { p-value }\end{array}$ & $\begin{array}{l}\text { sex:genotype } \\
\text { p-value }\end{array}$ \\
\hline BMD $\left[\mathrm{mg} / \mathrm{cm}^{2}\right]$ & $48 \pm 5$ & $50 \pm 6$ & $50 \pm 4$ & $49 \pm 5$ & 0.651 & 0.933 & 0.682 & 0.82 & 0.22 \\
\hline BMC [mg] & $375 \pm 59$ & $258 \pm 84$ & $486 \pm 86$ & $438 \pm 89$ & 0.002 & 0.412 & $<0.001$ & $<0.001$ & 0.113 \\
\hline Bone content [\%] & $1.60 \pm 0.20$ & $1.22 \pm 0.37$ & $1.56 \pm 0.23$ & $1.49 \pm 0.26$ & 0.003 & 0.885 & 0.003 & 0.142 & 0.042 \\
\hline Body length $[\mathrm{cm}]$ & $9.41 \pm 0.21$ & $9.32 \pm 0.20$ & $9.64 \pm 0.27$ & $9.66 \pm 0.31$ & 0.774 & 0.997 & 0.587 & $<0.001$ & 0.423 \\
\hline Body weight [g] & $23.53 \pm 1.98$ & $21.12 \pm 1.61$ & $31.06 \pm 3.39$ & $29.35 \pm 1.66$ & 0.038 & 0.223 & 0.002 & $<0.001$ & 0.579 \\
\hline Fat Mass [g] & $2.54 \pm 1.60$ & $1.20 \pm 1.41$ & $4.51 \pm 2.08$ & $3.66 \pm 2.07$ & 0.219 & 0.616 & 0.029 & $<0.001$ & 0.62 \\
\hline Lean Mass [g] & $15.95 \pm 1.65$ & $15.55 \pm 1.92$ & $20.77 \pm 3.30$ & $20.36 \pm 2.09$ & 0.97 & 0.968 & 0.527 & $<0.001$ & 0.989 \\
\hline
\end{tabular}

$\mathbf{F}$

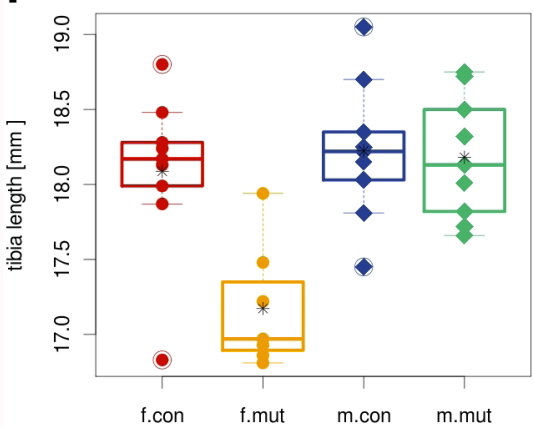

G

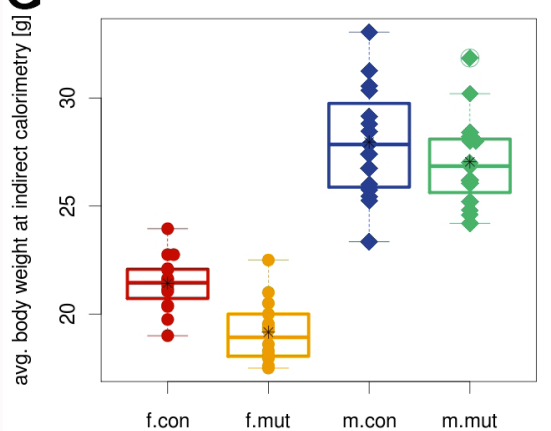

Figure 1. Zscan10 mutant females show decreased body weight. (A) Body mass time curve of mutant and control cohorts, $\mathrm{n}=60$. (B) Body weight boxplot with strip chart, split by sex and genotype. Bodyweight is significantly reduced in female mutant mice $(p=0.042)$. (C) Bodyweight means, standard deviation and p-values calculated by a linear model (D) Body composition analysis by NMR: means, standard deviation and p-values of a linear model. (E) DXA analysis: Group means, standard derivation and ANOVA (Tukey multiple comparisons of means). (F) Tibia length box plot with strip chart. Split by sex and genotype. Tibia length is significantly reduced in female mutant mice. (G) Indirect calorimetry: Average body weight at indirect calorimetry boxplot with strip chart, split by sex and genotype. Points are individual animals; circles represent females (f); diamonds represent males $(\mathrm{m})$ of Zscan10 homozygous mutants (mut) and wild type littermates (con). Line within the boxplot represents median. Box represents the $25 \%$ and $75 \%$ quartile. Asterix represents the mean. Circled points: Values outside the upper whisker $(\min (\max (\mathrm{x}), 75 \%$ quantile + $1.5 * \mathrm{IQR})$ and outside the lower whisker $(\max (\min (\mathrm{x}), 25 \%$ quantile $+1.5 * \mathrm{IQR})=$ outliers. IQR $=$ interquartile range $(75 \%$ quantile-25\% quantile). doi:10.1371/journal.pone.0104568.g001 
content was observed in female mutants (see Figure 1E). The tibia length was significantly reduced in female mice (see Figure $1 \mathrm{~F}$ ).

\section{Abnormalities of Zscan 10 homozygous mutant mice revealed by immunological, hematological and clinical chemistry screening}

The clinical-chemical and hematological screen detected several changes indicating effects of the Zscan10 mutation on renal function as well as platelet number and morphology. The glucose metabolism and tolerance was unaffected in an intraperitoneal glucose tolerance test (IpGTT) (data not shown). Zscan10 mutant mice presented with moderately decreased chloride and mildly reduced albumin concentration in plasma, while creatinine and urea levels were increased in these mice compared to controls (see Figure 2A). Plasma lactate dehydrogenase (LDH) activity generally present in body tissues, such as blood cells and heart muscle, is released upon tissue damage, and therefore a valuable indicator thereof. LDH activity was significantly increased in female mutant mice, while it tended to be lower in mutant males (see Figure 2B). Calcium was decreased in male mutants compared to male controls, while no effect was observed in the female cohorts (see Figure 2C). Alkaline phosphatase (ALP) activity was not increased in mutant animals (see Figure 2C). No significant effect on red blood cell count or morphology was observed, platelet counts were significantly decreased and the mean platelet volume (MPV) was increased in Zscan10 mutants (see Figure 2D,E,F). A higher frequency of T-cells in mutants went together with a lower $\mathrm{CD}^{+}$/ $\mathrm{CD}^{+}$ratio. The frequency of $\mathrm{CD} 25$-expressing cells within the $\mathrm{CD}^{+}{ }^{+} \mathrm{T}$-cell cluster, the frequency of $\mathrm{CD} 1 \mathrm{lb}$ expressing cells within the NK-cell cluster, and the frequency of MHC class IIexpressing cells within the B-cell cluster was higher in mutants, also higher levels of IgG1, IgG2b and an increased ratio of IgG1/ IgG2b was detected in mutants. Plasma IgE levels were unaffected (see Figure S2). Concentrations of corticosterone, androstendione and testosterone in the plasma of Zscan10 mutant and control mice aged 16 weeks revealed a statistically significant decrease in corticosterone levels in male mutants (see Figure 2G).

\section{Neurological and behavioral abnormalities in Zscan10 homozygous mutant mice}

Female mutant mice showed increased locomotor activity (total distance travelled) and increased locomotor speed $(\mathrm{p}<0.05)$ in the open field and entered the center more frequently while male mutant mice showed the opposite effect (interactions genotype $\mathrm{x}$ sex: $\mathrm{p}<0.05$ ) (see Figure 3A,B,C and Figure S3). Male mutant mice also exhibited increased PPI and female mutants exhibited an increase in acoustic startle reactivity at higher sound pressure levels (data not shown).

SHIRPA is a standardized observation protocol for assessment of genetically modified mice. During this test increased occurrence of urination was detected for two thirds of the mutant cohort, compared to only one third of the wild type mice $(p=0.00921$, $\mathrm{n}=30$ ). Measuring grip strength for the evaluation of muscle function revealed reduced force in 2- and 4-paw measurement. However, the mutant mice were also significantly lighter (see Figure $1 \mathrm{~A}, \mathrm{~B}, \mathrm{C}$ ) and including body mass as a confounding factor into statistical analysis confirmed body mass as the main effect on grip strength. During Rota rod analysis, mutants fell off the Rota rod more often while controls rotated passively, a behavior also rated as a failure thus leading to manual timer stop. This difference in the strategy on the rod, however, had no influence on mean latencies (data not shown). Other parameters covering overall appearance, movement and reflexes were without any significance.

\section{Reduced eye size in Zscan 10 homozygous mutant mice}

Significantly reduced eye sizes in both male and female Zscan 10 mutants were detected, present already at midgestation (see Figure 4A-D and data not shown). Laser interference biometry revealed significantly reduced axial eye lengths in mutants of both sexes $(\mathrm{P}<0.0001)$ (see Figure 4E). Borderline significant increased opacification of left and right lenses of male and female mutants, respectively, was observed. Scheimpflug imaging indicated significantly increased mean lens density between controls and mutants, yet with a surprising unilateral restriction to left eyes in mutant males $(p=0.002)$ and right eyes in mutant females $(p=0.016)$ (see Figure 4F,G). Optical coherence tomography demonstrated a normally developed fundus with no significant alteration in the number of main blood vessels or retinal thickness in the posterior part of the eye. While male mutants showed regular responses to the moving stripe pattern in the virtual drum vision test, female mutants showed a reduced response with a borderline significance $(p=0.034)($ see Figure 4H).

\section{Further phenotypic findings in Zscan10 homozygous mutant mice}

Awake echocardiography of Zscan 10 homozygous mutants and respective controls revealed increased systolic left ventricular internal dimensions (LVIDs) and a decreased respiration rate mainly in male mutants. Further, Zscan10 mutants showed a decreased heart rate when compared with control mice (data not shown). Thus, only mild genotype-related differences without relevance for the cardiovascular system were found. Lung function screening showed a slight yet significant but functionally rather irrelevant decreased dynamic compliance $(p=0.026)$ and tidal volume $(p=0.004)$ (data not shown). Body temperature showed a tendency to be slightly lower in male mutants (data not shown).

In homozygous male mutant mice an increase in liver weight normalized to body weight was determined (see Figure 5A). A slightly reduced absolute and normalized spleen and heart weight in particular in female mutants was observed (see Figure 5B-E, and Figure S4), yet no morphological changes of internal organs were detected during histological analysis.

\section{Zscan10 expression in midgestation embryos supports phenotypic findings}

Phenotypically affected organs in the screen performed by GMC led us to revisit embryonic and adult Zscan10 expression. Since expression pattern analysis was previously established by WISH [3,6], a technique prone to probe entrapment, lack of proper penetration of the probe and other obstacles, SISH was performed. A 270 bp probe essentially spanning exons 3 to 5 and a $1.35 \mathrm{~kb}$ probe essentially covering exon 2 to the proximal part of exon 6 was used and compared with an EGFP probe reflecting the pUPA reporter gene expression (see Figures S1 and S6). As determined by repeat masker (www.repeatmasker.org), the Zscan10 probes were free of repetitive elements and specific to $Z$ scan 10. In several independent experiments $(\mathrm{n}=6)$ we observed a punctate expression pattern (a positive cell surrounded by numerous non-expressing cells) in E12.5 and E15.5 embryos, namely in kidneys, heart, liver, muscle and developing bones of the forelimb, but in a similar matter in neural tissue like the neural tube, the brain and in dorsal root ganglia and sensory organs like the eye (see Figure 6B,D-K). Strongest expression of such kind was located in the linings of stomach and gut (see Figure 6D,E,G). This 
A

\begin{tabular}{|c|c|c|c|c|c|c|c|}
\hline & \multicolumn{2}{|c|}{ female } & \multicolumn{2}{|c|}{ male } & \multicolumn{3}{|c|}{ Linear model } \\
\hline & $\begin{array}{c}\begin{array}{c}\text { control } \\
n=15\end{array} \\
\text { mean } \pm s d\end{array}$ & $\begin{array}{c}\text { mutant } \\
n=13 \\
\text { mean } \pm s d\end{array}$ & $\begin{array}{c}\begin{array}{c}\text { control } \\
n=14\end{array} \\
\text { mean } \pm s d\end{array}$ & $\begin{array}{c}\text { mutant } \\
n=15 \\
\text { mean } \pm s d\end{array}$ & $\begin{array}{l}\text { genotype } \\
\text { p-value }\end{array}$ & $\begin{array}{c}\text { sex } \\
\text { p-value }\end{array}$ & $\begin{array}{c}\text { genotype:sex } \\
\text { p-value }\end{array}$ \\
\hline Sodium [mmoVl] & $147 \pm 2$ & $145 \pm 5$ & $150 \pm 1$ & $148 \pm 3$ & 0.054 & 0.002 & 0.871 \\
\hline Potassium [mmol/] & $3.8 \pm 0.3$ & $3.6 \pm 0.3$ & $4.1 \pm 0.3$ & $4.2 \pm 0.2$ & 0.484 & $<0.001$ & 0.14 \\
\hline Chloride [mmoll] & $111.8 \pm 1.7$ & $108 \pm 3.7$ & $111.3 \pm 1.5$ & $108.9 \pm 2.4$ & $<0.001$ & 0.721 & 0.274 \\
\hline Total protein [g/l] & $54.3 \pm 2.3$ & $53.1 \pm 2.5$ & $53.2 \pm 2.4$ & $52.7 \pm 2.8$ & 0.192 & 0.228 & 0.629 \\
\hline Albumin $[g /]$ & $29.5 \pm 1.2$ & $28.1 \pm 1.5$ & $27.4 \pm 1.4$ & $26.3 \pm 1.9$ & 0.002 & $<0.001$ & 0.695 \\
\hline Creatinine enz. [mumoll] & $15.31 \pm 1.47$ & $16.22 \pm 1.04$ & $16.08 \pm 1.09$ & $16.98 \pm 1.44$ & 0.011 & 0.029 & 0.987 \\
\hline Urea [mmoVl] & $10.7 \pm 0.98$ & $12.52 \pm 2.06$ & $10.42 \pm 1.36$ & $11.44 \pm 0.93$ & $<0.001$ & 0.071 & 0.279 \\
\hline
\end{tabular}

B

\begin{tabular}{|c|c|c|c|c|c|c|c|}
\hline & \multicolumn{2}{|c|}{ female } & \multicolumn{2}{|c|}{ male } & \multicolumn{3}{|c|}{ Linear model } \\
\hline & $\begin{array}{c}\text { control } \\
n=15 \\
\text { mean } \pm s d\end{array}$ & $\begin{array}{c}\text { mutant } \\
\mathrm{n}=13 \\
\text { mean } \pm \mathrm{sd}\end{array}$ & $\begin{array}{c}\text { control } \\
n=14 \\
\text { mean } \pm \text { sd }\end{array}$ & $\begin{array}{c}\text { mutant } \\
\mathrm{n}=15 \\
\text { mean } \pm \mathrm{sd}\end{array}$ & $\begin{array}{l}\text { genotype } \\
\text { p-value }\end{array}$ & $\begin{array}{l}\text { sex } \\
\text { p-value }\end{array}$ & genotype:sex \\
\hline Cholesterol [mmoll] & $2.04 \pm 0.224$ & $1.945 \pm 0.246$ & $2.481 \pm 0.36$ & $2.53 \pm 0.195$ & 0.745 & $<0.001$ & 0.308 \\
\hline Triglyceride [mmoll] & $1.212 \pm 0.382$ & $1.178 \pm 0.466$ & $1.279 \pm 0.372$ & $1.25 \pm 0.372$ & 0.765 & 0.511 & 0.981 \\
\hline ALAT/GPT [U/]] & $25 \pm 3$ & $33 \pm 11$ & $40 \pm 14$ & $41 \pm 18$ & 0.135 & 0.001 & 0.322 \\
\hline ASAT/GOT [U/] & $51 \pm 7$ & $60 \pm 17$ & $74 \pm 46$ & $58 \pm 22$ & 0.642 & 0.175 & 0.087 \\
\hline alpha-Amylase [U/] & $556.16 \pm 46.78$ & $574.7 \pm 83.22$ & $645.81 \pm 69.19$ & $673.69 \pm 59.97$ & 0.186 & $<0.001$ & 0.789 \\
\hline Glucose [mmoll] & $14.69 \pm 2.3$ & $13.62 \pm 2.29$ & $15.48 \pm 1.89$ & $15.41 \pm 2.26$ & 0.333 & 0.031 & 0.391 \\
\hline LDH [U/l] & $133.9 \pm 24.3$ & $168.4 \pm 32.9$ & $181.7 \pm 76.1$ & $132.8 \pm 54.1$ & 0.594 & 0.652 & 0.003 \\
\hline
\end{tabular}

\begin{tabular}{|c|c|c|c|c|c|c|c|}
\hline & \multicolumn{2}{|c|}{ female } & \multicolumn{2}{|c|}{ male } & \multicolumn{3}{|c|}{ Linear model } \\
\hline & $\begin{array}{c}\text { control } \\
n=15 \\
\text { mean } \pm s d\end{array}$ & $\begin{array}{c}\text { mutant } \\
\mathrm{n}=13 \\
\text { mean } \pm \mathrm{sd}\end{array}$ & $\begin{array}{c}\text { control } \\
n=14 \\
\text { mean } \pm \text { sd }\end{array}$ & $\begin{array}{c}\text { mutant } \\
\mathrm{n}=15 \\
\text { mean } \pm \text { sd }\end{array}$ & $\begin{array}{l}\text { genotype } \\
\text { p-value }\end{array}$ & $\begin{array}{c}\text { sex } \\
\text { p-value }\end{array}$ & $\begin{array}{c}\text { genotype:sex } \\
\text { p-value }\end{array}$ \\
\hline Calcium [mmoll] & $2.4 \pm 0.05$ & $2.38 \pm 0.11$ & $2.49 \pm 0.06$ & $2.4 \pm 0.07$ & 0.007 & 0.005 & 0.115 \\
\hline Inorganic phosphate [mmoVl] & $1 \pm 0.3$ & $1.1 \pm 0.3$ & $1.2 \pm 0.3$ & $1.2 \pm 0.3$ & 0.653 & 0.059 & 0.908 \\
\hline Iron [mumoVl] & $23.1 \pm 3$ & $21.6 \pm 4.2$ & $20.8 \pm 4.2$ & $20.5 \pm 3.1$ & 0.374 & 0.079 & 0.54 \\
\hline ALP [U/] & $137 \pm 13$ & $141 \pm 19$ & $82 \pm 8$ & $83 \pm 15$ & 0.491 & $<0.001$ & 0.72 \\
\hline
\end{tabular}

\begin{tabular}{|c|c|c|c|c|c|c|c|}
\hline & \multicolumn{2}{|c|}{ female } & \multicolumn{2}{|c|}{ male } & \multicolumn{3}{|c|}{ Linear model } \\
\hline & $\begin{array}{c}\text { control } \\
n=15 \\
\text { mean } \pm s d\end{array}$ & $\begin{array}{c}\text { mutant } \\
n=13 \\
\text { mean } \pm s d\end{array}$ & $\begin{array}{c}\text { control } \\
n=14 \\
\text { mean } \pm s d\end{array}$ & $\begin{array}{c}\text { mutant } \\
n=15 \\
\text { mean } \pm s d\end{array}$ & $\begin{array}{l}\text { genotype } \\
\text { p-value }\end{array}$ & $\begin{array}{c}\text { sex } \\
\text { p-value }\end{array}$ & $\begin{array}{c}\text { genotype:sex } \\
\text { p-value }\end{array}$ \\
\hline $\mathrm{RBC}\left[\mathrm{Mio} / \mathrm{mm}^{3}\right]$ & $10.98 \pm 0.31$ & $10.72 \pm 0.45$ & $10.93 \pm 0.4$ & $11.02 \pm 0.5$ & 0.458 & 0.238 & 0.122 \\
\hline $\mathrm{HGB}[\mathrm{g} / \mathrm{dl}]$ & $15.99 \pm 0.43$ & $15.78 \pm 0.62$ & $15.66 \pm 0.58$ & $15.62 \pm 0.71$ & 0.452 & 0.123 & 0.603 \\
\hline HCT [\%] & $56.67 \pm 2.14$ & $56.82 \pm 2.89$ & $56.86 \pm 2.98$ & $56.85 \pm 3.28$ & 0.924 & 0.888 & 0.92 \\
\hline MCV [fl] & $51.6 \pm 1.92$ & $53.08 \pm 1.93$ & $52.14 \pm 2.21$ & $51.6 \pm 1.64$ & 0.366 & 0.366 & 0.054 \\
\hline $\mathrm{MCH}[\mathrm{pg}]$ & $14.55 \pm 0.37$ & $14.73 \pm 0.55$ & $14.33 \pm 0.34$ & $14.18 \pm 0.28$ & 0.891 & 0.001 & 0.126 \\
\hline $\operatorname{MCHC}[\mathrm{g} / \mathrm{dl}]$ & $28.21 \pm 0.65$ & $27.81 \pm 0.83$ & $27.6 \pm 0.73$ & $27.52 \pm 0.58$ & 0.202 & 0.019 & 0.393 \\
\hline RDW [\%] & $12.97 \pm 0.4$ & $12.89 \pm 0.5$ & $13.08 \pm 0.35$ & $13.25 \pm 0.66$ & 0.722 & 0.081 & 0.333 \\
\hline WBC $\left[10^{3} / \mathrm{mm}^{3}\right]$ & $5.98 \pm 1.1$ & $5.54 \pm 1.39$ & $7.56 \pm 1.83$ & $9.16 \pm 1.18$ & 0.122 & $<0.001$ & 0.008 \\
\hline $\operatorname{PLT}\left[10^{3} / \mathrm{mm}^{3}\right]$ & $1080.73 \pm 122.06$ & $966.92 \pm 73.39$ & $1176.14 \pm 164.99$ & $1107.13 \pm 185.23$ & 0.021 & 0.003 & 0.562 \\
\hline MPV [fl] & $4.92 \pm 0.08$ & $5.15 \pm 0.16$ & $4.86 \pm 0.09$ & $5.09 \pm 0.16$ & $<0.001$ & 0.089 & 0.881 \\
\hline
\end{tabular}
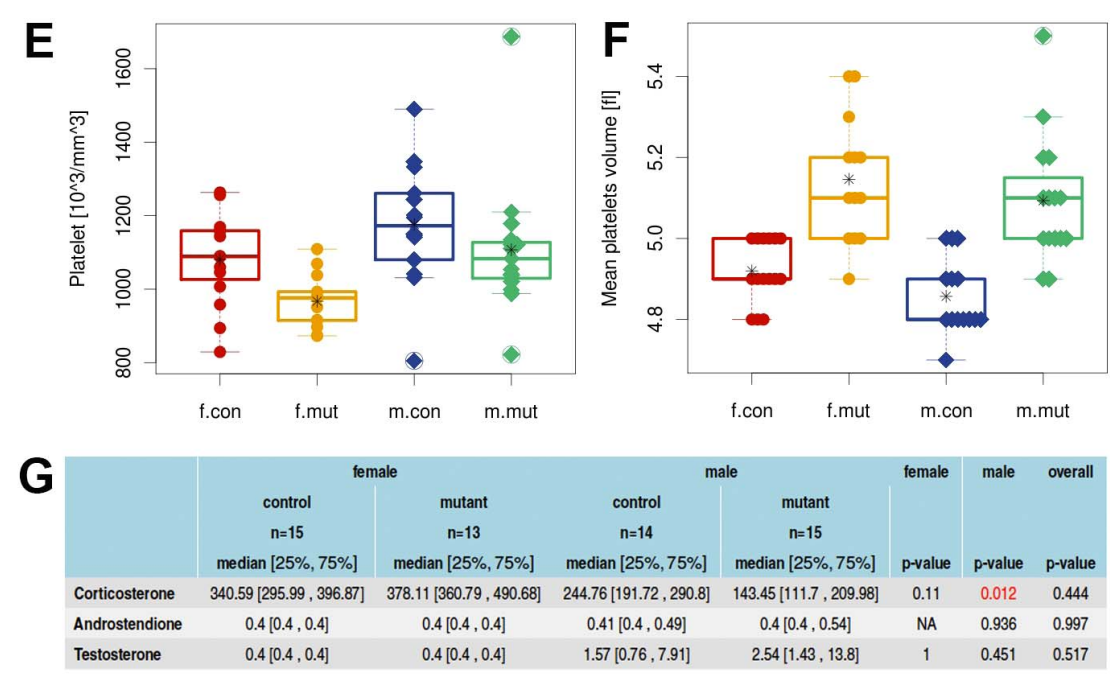
Figure 2. Hematological and clinical chemistry analysis. (A) Plasma electrolyte, protein, creatinine and urea concentrations of ad libitum fed mice. (B) Lipid and glucose levels as well as selected enzyme activities in plasma of ad libitum fed mice. (C) Plasma concentrations of minerals, iron and ALP activity of ad libitum fed mice. (D) Values obtained from EDTA-blood samples. Means, standard deviations and p-values for genotype, sex and genotype $x$ sex interaction effects calculated by a linear model (A-D). Platelet (E) and mean platelet volume (F) boxplot strip chart, split by sex and genotype. (G) Concentration of steroid hormones in plasma: Medians, first and third quartile and p-values calculated by a Wilcoxon rank-sum test $(n=57)$. Points are individual animals; circles represent females ( $f)$; diamonds represent males $(\mathrm{m})$ of $Z$ scan 10 homozygous mutants (mut) and wild type littermates (con). Line within the boxplot represents median. Box represents the $25 \%$ and $75 \%$ quantile. Asterix represents the mean. Circled points: Values outside the upper whisker $(\min (\max (x), 75 \%$ quantile $+1.5 * \mid \mathrm{QR})$ and outside the lower whisker $(\max (\min (\mathrm{x}), 25 \%$ quantile+1.5*IQR) $=$ outliers. IQR = interquartile range $(75 \%$ quantile- $25 \%$ quantile).

doi:10.1371/journal.pone.0104568.g002

punctate expression pattern for Zscan10 was still observed in the organs of adult mice as shown for sections of the heart, kidney and eye (see Figure 7). Expression of the pUPA reporter gene EGFP coincided with Zscan10 expression (see Figure S6M-X). The bHLH transcription factor Hes5 [27], a downstream effector in the Notch pathway [28] involved in eye, especially retinal development [29], appeared reduced in its signal strength in the Zscan $10^{-1-}$ mutant retina versus that of a heterozygous littermate, yet this would require further quantitative analysis (see Figure S6C,I). No change in expression for Hes 5 was observed in other organs analyzed. Sox 2 was found expressed in the heart, neural tube and eye similar to, but at much lower levels than Zscan10, equivalent expression was observed in the apical ectodermal ridge. No coexpression was detected in the vertebrate body and for the homozygous mutant in kidney and adrenal (see Figure S6Y- $\mathrm{P}^{\prime}$ ).

\section{Discussion}

Zscan10 was originally discovered in screens of human and mouse ESC to identify genes with relevance in maintaining a pluripotent state of these cells. The established interaction of Zscan 10 with known pluripotency markers like Oct4 and Sox2 in ESC suggested a potentially crucial role of Zscan 10 in early mouse development [1]. Oct4 is a homeodomain transcription factor of the POU family, highly expressed in ESG and with a critical function in maintaining pluripotency [30]. In its absence an ICM does not form [31]. Oct4 becomes silenced upon differentiation with the exception of its requirement for the viability of germ cells [32]. Ectopic expression of Oct4 from the ROSA26 locus resulted in dysplasia in the gastrointestinal tract and skin due to an increase in progenitor cells [33]. Oct4 is capable of heterodimerization with Sox2, a transcription factor and member of the SRY-related
HMG-box (Sox) family. Heterozygous mutations in the Sox2 gene have been linked to eye malformations like anophthalmia and microphthalmia [34,35]. Sox2 is further known to interact with Pax6, a master control gene during eye development $[36,37,38]$ with pleiotropic effects in mouse and human when mutated amongst some are the proliferative control of neural stem or progenitor cell populations [39] and pancreatic $\alpha$-cell development [40]. Notably the pancreas and spleen originate from a shared embryonic lineage [41].

\section{Zscan 10 mutants partially phenocopy Sox 2 and Pax6 hypomorphs}

We have successfully generated fertile homozygous mutant mice for Zscan10 using the gene trap clone \#285B6 obtained from CMMR. Our initial phenotype assessment indicated a slight decrease in the number of homozygous mutant females at weaning age as well as a size reduction in homozygous mutant mice. A more detailed phenotype analysis conducted by the GMC confirmed significantly reduced body weight, a significant reduction in absolute heart weight, tibia length, and a reduced bone mineral content was observed in homozygous female mutants, however ALP activity was not increased in mutant animals as usually seen in mice with increased bone turnover. Furthermore a significant reduction in absolute spleen weight in both genders was noted, while the liver weight was only significantly increased in homozygous males.

A detailed eye screen conducted by GMC identified a significant reduction in the eye size and axial eye length in both genders. There was also a borderline significantly increased opacification, yet no abnormalities in retinal layers or vascularization of the fundus of homozygous mutants. Overall, this resulted in reduced vision in the female mutants. Aniridia, anophthalmia and microphthalmia have been associated with
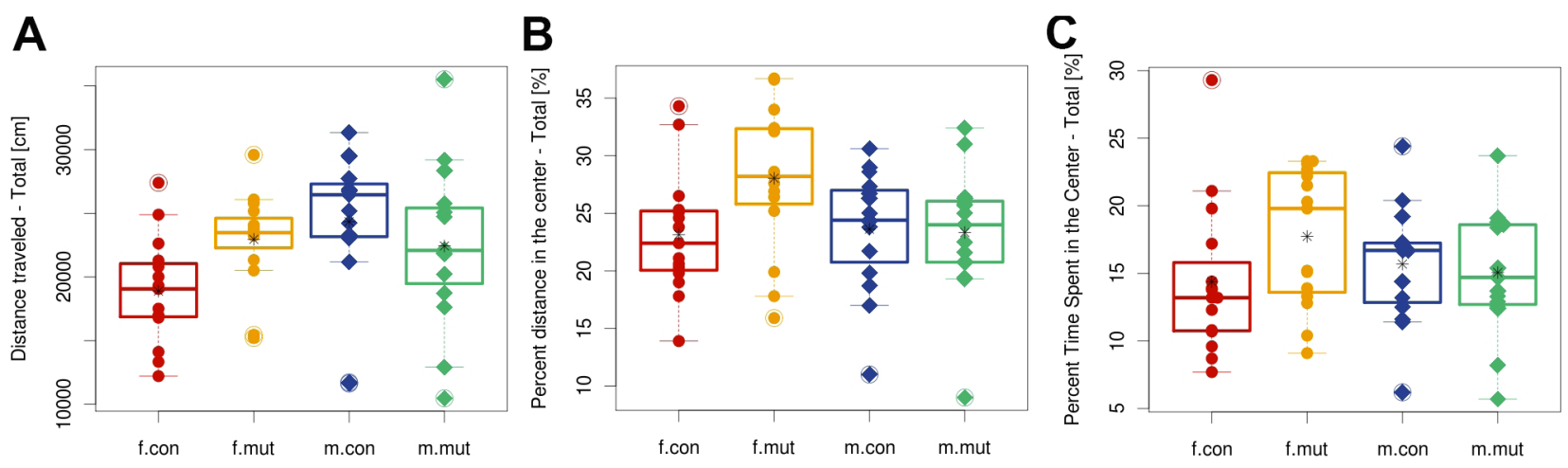

Figure 3. Open Field Testing. Distance traveled (A), percent distance in the center (B) and percent time spent in the center (C). Total boxplot with strip chart, split by sex and genotype. Points are individual animals; circles represent females (f); diamonds represent males (m) of Zscan 10 homozygous mutants (mut) and wild type littermates (con). Line within the boxplot represents median. Box represents the $25 \%$ and $75 \%$ quantile. Asterix represents the mean. Circled points: Values outside the upper whisker $(\min (\max (\mathrm{x}), 75 \%$ quantile $+1.5 * \mathrm{IQR})$ and outside the lower whisker $(\max (\min (x), 25 \%$ quantile+1.5*IQR) $=$ outliers. IQR = interquartile range $(75 \%$ quantile- $25 \%$ quantile).

doi:10.1371/journal.pone.0104568.g003 

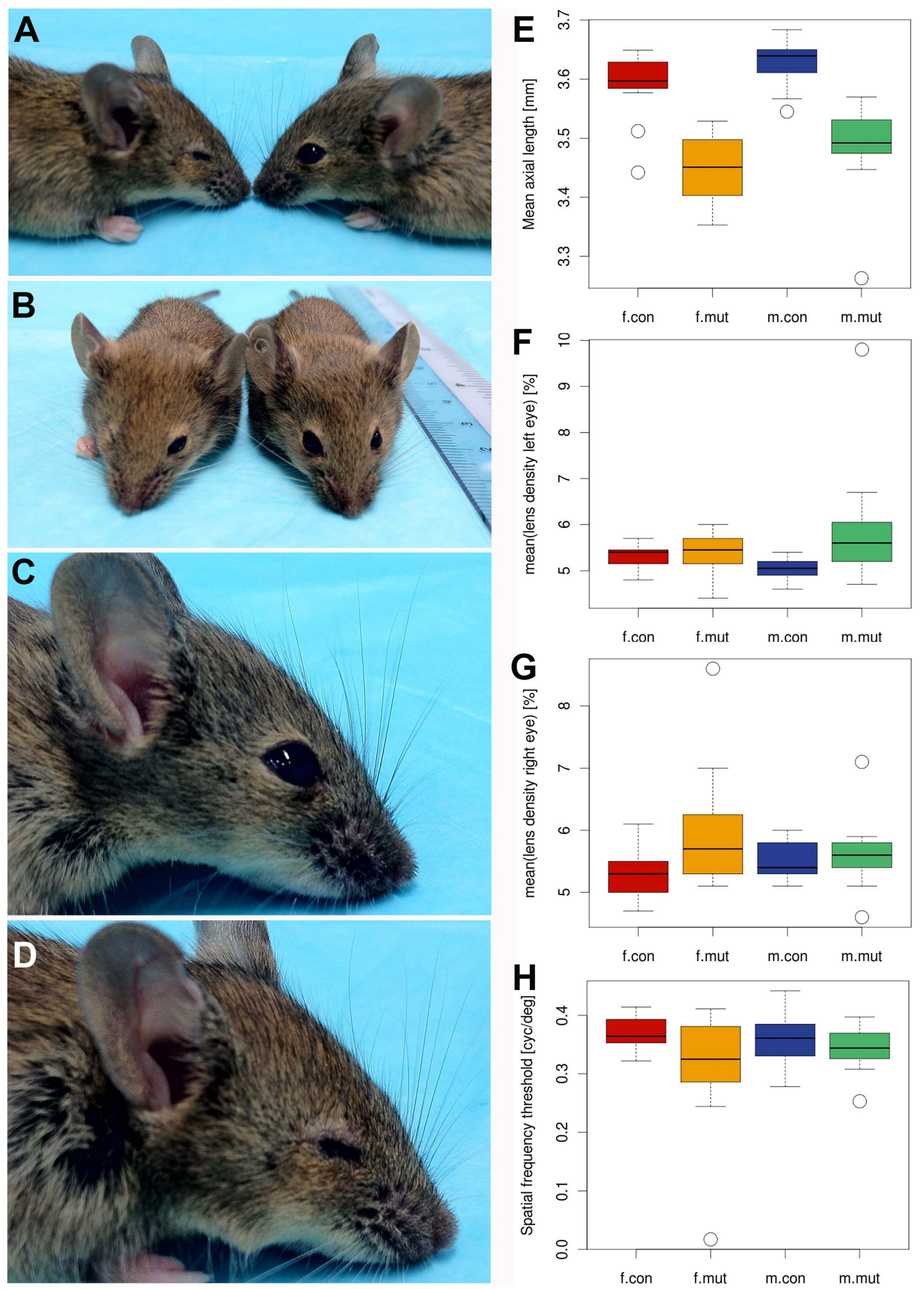
Figure 4. Small eye phenotype in Zscan10 homozygous mutant mice. Lateral (A) and frontal (B) view of adult mutant (left) and wild type (right) mice. Lateral view of right eye of a wild type (C) and mutant (D) adult female. (E) Eye size measurements by laser interference biometry revealed significantly reduced axial eye length in mutants of both sexes $(p<0.001)$. Anterior eye investigation by Scheimpflug imaging indicated significantly increased mean lens density between controls and mutants for left eyes in males $(p=0.002)(F)$ and right eyes in females $(p=0.016)(G)$. Virtual drum vision testing showed a reduced response with borderline significance in female mutants $(p=0.034)(H)$. (E) to $(H)$ are displayed as boxplot split by sex and genotype. Outliers are indicated by open circles.

doi:10.1371/journal.pone.0104568.g004

haploinsufficiency of SOX2 while anterior eye defects, including defects of the iris and ciliary body have been associated with haploinsufficiency of PAX6 in humans [34,37,42,43,44,45,46,47].
Analysis of eye development in Sox2 hypomorphic mice indicated variable degrees of microphthalmia attributed to abnormal neural progenitor proliferation, consistent with findings in human [48]. A

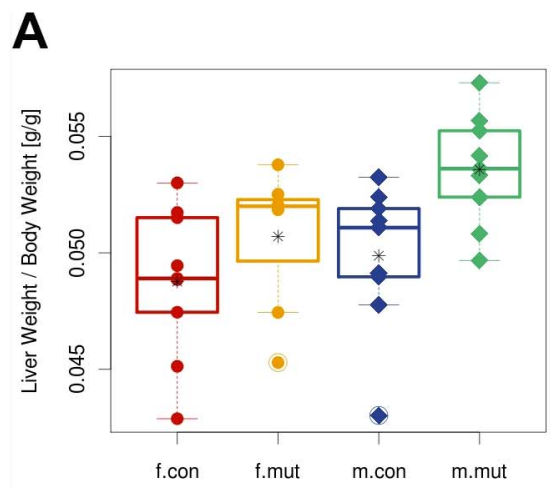

B

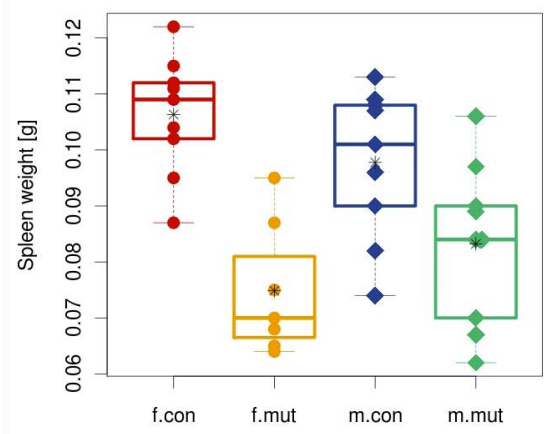

D

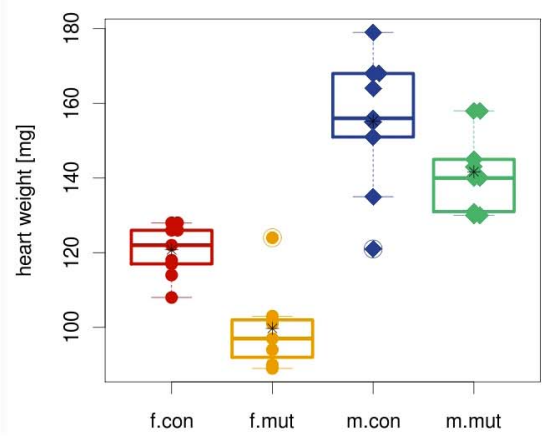

C

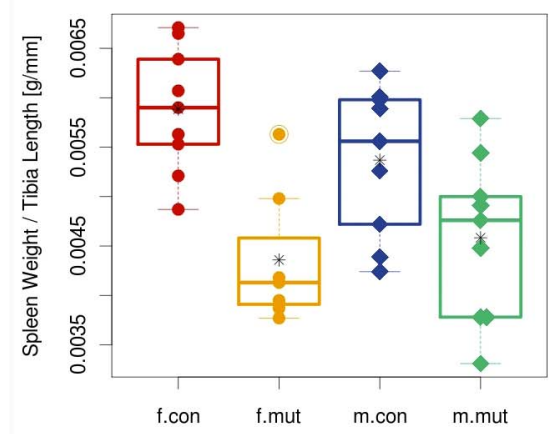

$\mathbf{E}$

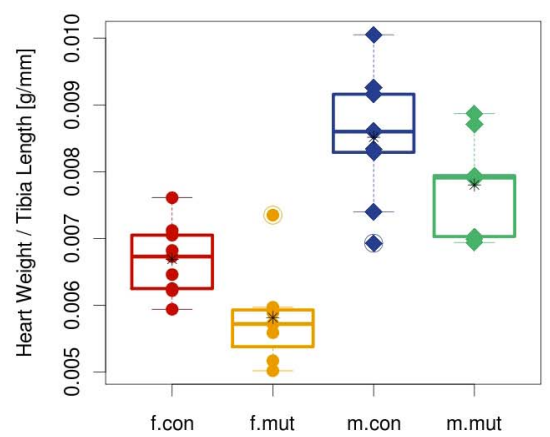

Figure 5. Organ weight determined in pathology screen. (A) Normalized liver weight is significantly increased in male mutant mice (P=0.008). (B) Absolute spleen weight is significantly reduced in mutant mice of both genders. (C) Normalized spleen weight is significantly reduced in female mutant mice $(P=0.002)$. ( $D)$ Absolute heart weight is significantly reduced in female mutant mice $(p=0.003)$. ( $E)$ Normalized heart weight is significantly reduced in female mutant mice $(p=0.016)$. All results demonstrated as boxplot with strip chart, split by sex and genotype. For tibia length refer to Figure 1F. Points are individual animals; circles represent females ( $\mathrm{f}$ ); diamonds represent males (m) of Zscan10 homozygous mutants (mut) and wild type littermates (con). Line within the boxplot represents median. Box represents the $25 \%$ and $75 \%$ quantile. Asterix represents the mean. Circled points: Values outside the upper whisker $\left(\min \left(\max (x), 75 \%\right.\right.$ quantile $\left.+1.5^{*} \mid \mathrm{QR}\right)$ and outside the lower whisker $(\max (\min (\mathrm{x}), 25 \%$ quantile $+1.5 * \mathrm{QQR})=$ outliers. IQR $=$ interquartile range $(75 \%$ quantile $-25 \%$ quantile).

doi:10.1371/journal.pone.0104568.g005 
A

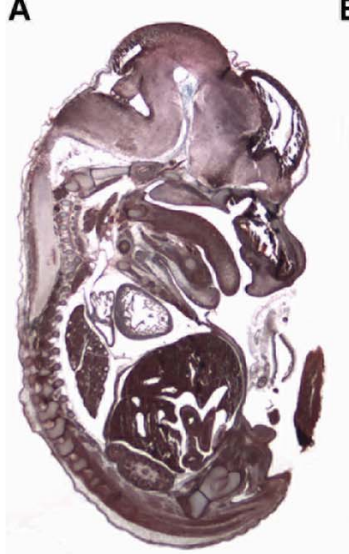

B

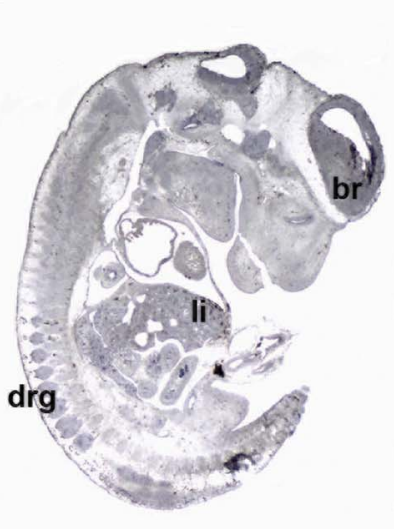

C
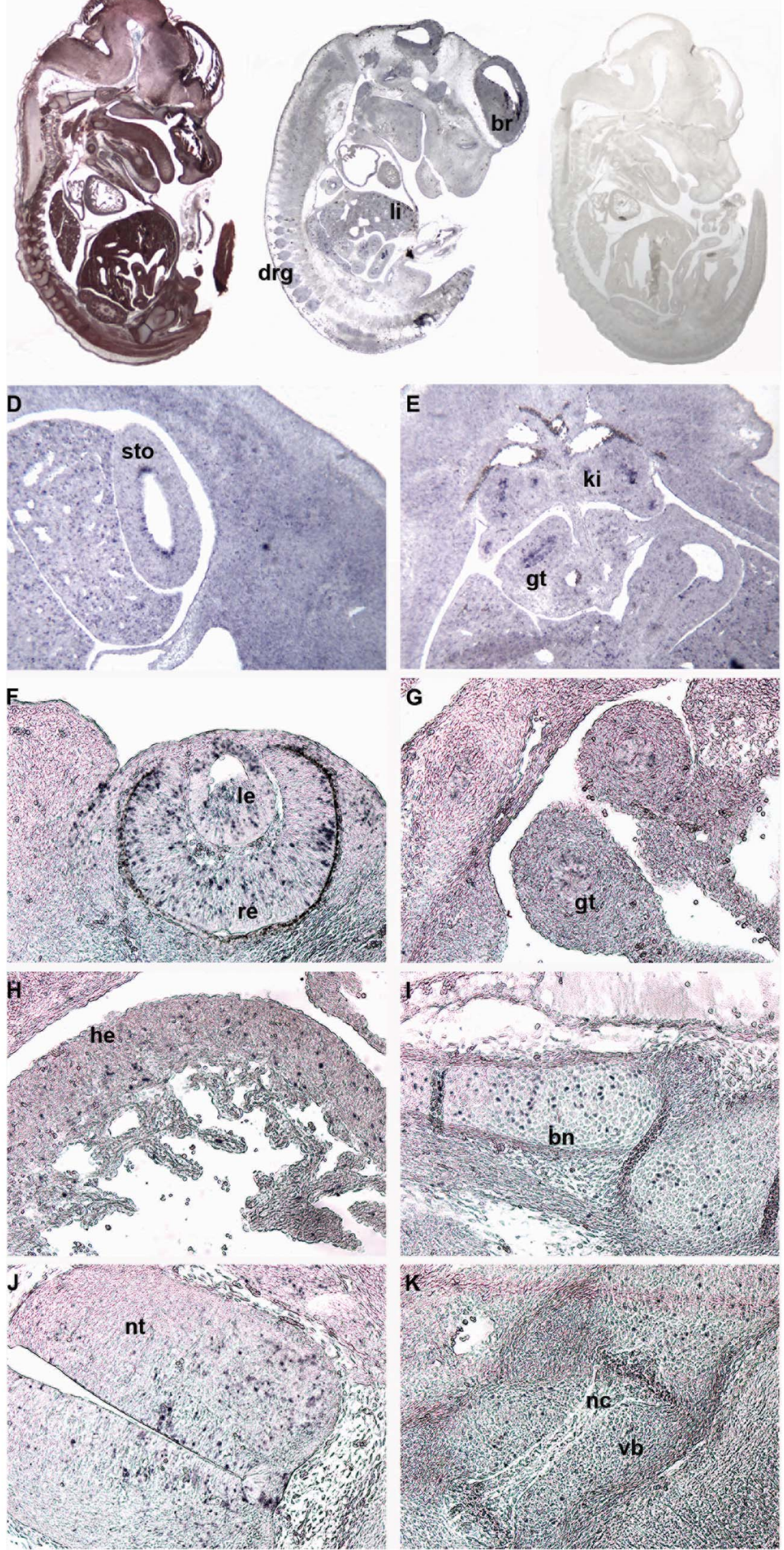

Figure 6. Punctuated Zscan10 expression in E12.5 wild type embryos as determined by SISH. Sagittal sections through E12.5 wild type embryos for reference as Mallory tetrachrome staining (A), with T7 antisense probe (B) and T3 sense probe (C). T7 antisense probe on transverse sections reflecting Zscan 10 expression in the lining of the stomach (D), kidney and lining of the gut $(E)$ at $4 x$; on sagittal sections through the eye $(F)$, 
lower abdomen $(\mathrm{G})$, heart $(\mathrm{H})$, humerus $(\mathrm{I})$ and vertebral body $(\mathrm{K})$, as well as transverse sections through the neural tube $(\mathrm{J})$ at $10 \mathrm{x}$. All pictures were taken on a Motic compound microscope with a Motic Moticam 2.0MP digital camera. Brain (br), liver (li), dorsal root ganglia (drg), stomach (sto), kidney (ki), gut (gt), lens (le), retina (re), heart (he), bone (bn), neutral tube (nt), notochord (nc) and vertebral body (vb).

doi:10.1371/journal.pone.0104568.g006

follow up study with conditional Sox2 mutant mice revealed an inversely correlated gradient between Sox2 and Pax6 expression in the developing optic cup and demonstrated the importance of the functional antagonism between Sox2 and Pax6 during patterning of the eye cup [49]. Hes5 is a known downstream effector in the Notch pathway, important in the cell fate decision of retinal progenitor cell populations [29]. We observed a slightly reduced expression of Hes 5 in Zscan 10 mutant retinas. The previously demonstrated physical in vitro interaction between Zscan10 and Sox2 [1], the coexpression of Zscan10 and Sox2 demonstrated here in the eye and the small eye phenotype identified during the GMC phenotyping screen nominates Zscan10 as a new player in the concerted interaction of transcription factors during eye development.

\section{Altered platelet counts and an activated immune status in Zscan10 homozygous mutants}

The finding, that a slightly decreased platelet count is associated with an increase mean platelet volume (MPV) in Zscan10 mutant mice compared to controls, fits to the observation that these parameters are usually negatively correlated [50,51]. Increased MPV values and the occurrence of "large platelets" can indicate changes in cytoskeletal structures or an increased proportion of pre-platelets and pro-platelets (prePLT, proPLT) as well as young platelets, which can occur in response to thrombopenia [51]. Increased platelet size goes together with higher platelet reactivity and is associated with diabetes mellitus and an increased risk of cardiovascular diseases in humans and is therefore considered as an important diagnostic marker [50,52,53]. A recent GWAS study identified 68 loci associated with platelet number and volume [54]. The slightly decreased platelet count in homozygous Zscan10 mutants associated with increased MPV values could therefore result from changes in number and function of megakaryocytes which could be in line with the suggested role of Zscan10 in maintaining sufficient numbers of progenitor cells - resulting in effects on cell differentiation, platelet formation or platelet maturation. A decrease in the number of megakaryocytes could be compensated by an increased activity of these cells leading to the observed differences, as it was described for the response to pharmacologically induced thrombopenia [50,51]. On the other hand these changes could occur due to changes in cytoskeletal structure or secondarily to an increased platelet consumption or destruction. Further investigations are necessary to elucidate the underlying cause.

\section{Zscan10 homozygous mutant mice display behavioral alterations}

The Open Field Test was originally described to study emotionality in rats [55] with emotional rats executing fewer entries in the central part of the test arena and higher levels of defecation. Glucocorticoid hormone levels can be indicative of stress tolerance with corticosterone levels being elevated during periods of stress [56,57]. The acoustic startle response and PPI measure auditory sensorimotor integration and an increased acoustic startle response can be indicative of increased anxiety levels. Impaired PPI has been associated with human disorders
A
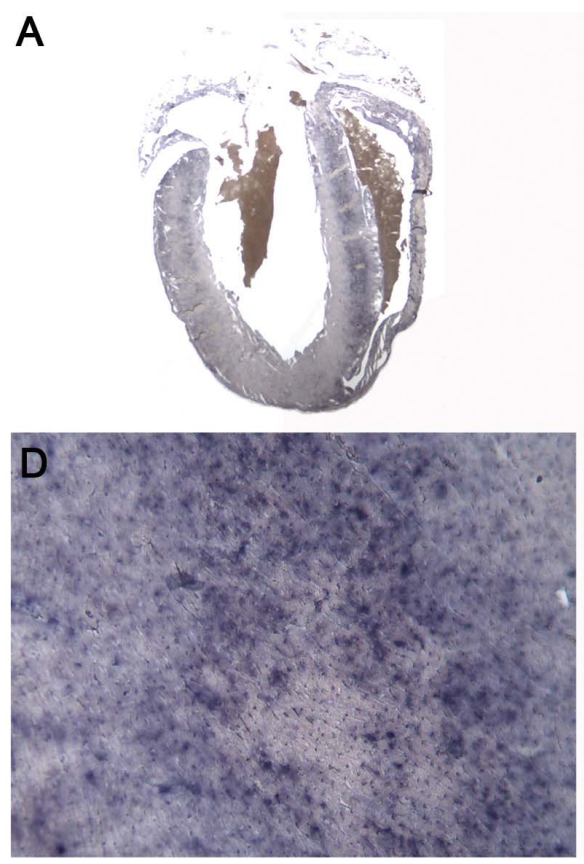

B
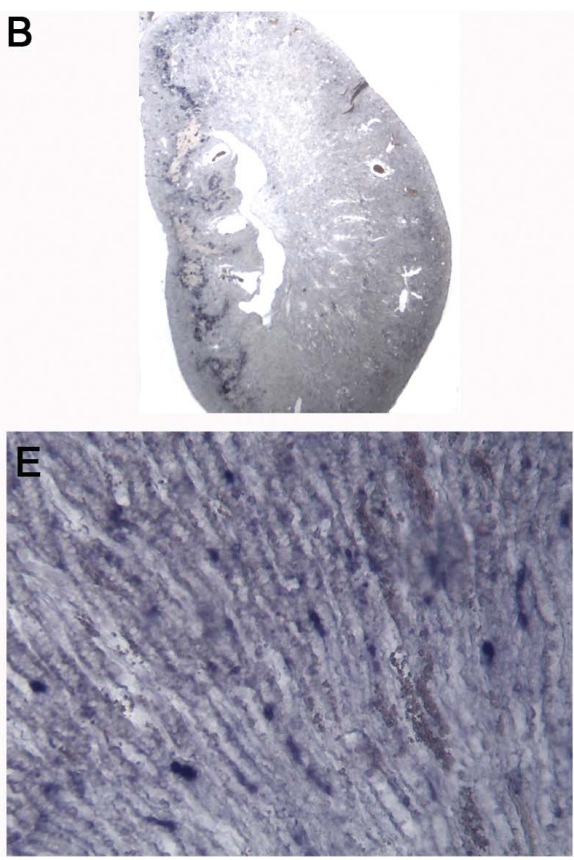

C

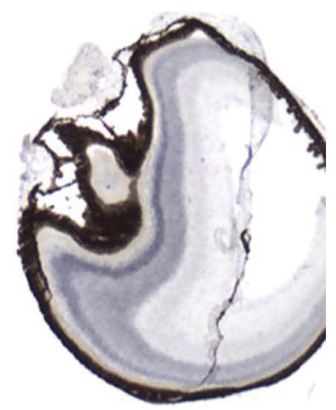

$\mathbf{F}$

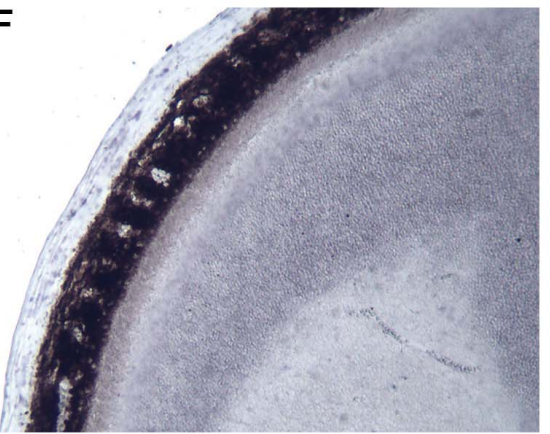

Figure 7. Punctuated Zscan10 expression persists in adult tissue. SISH on sections through heart $(\mathrm{A}, \mathrm{D})$, kidney $(\mathrm{B}, \mathrm{E})$ and eye $(\mathrm{C}, \mathrm{F})$ probed with the T7 Zscan 10 antisense probe taken at $0.63 \times(A, B)$ and $2.5 \times(C)$ on a Leica S6 dissecting scope and magnifications thereof $(D, E, F)$ taken on a Motic compound microscope at $10 \times$ all documented with a Motic Moticam 2.0MP digital camera.

doi:10.1371/journal.pone.0104568.g007 
such as: schizophrenia, Huntington's disease, fragile X syndrome and autism and involves amongst other signaling centers the limbic cortex [58,59]. The GMC steroid screen at 16 weeks of age indicated decreased corticosterone levels in plasma of Zscan10 homozygous male mutant mice, and a trend in the opposite direction in female mutants. Significantly increased urination was observed in Zscan10 mutants, female Zscan10 mutants were slightly more active in the OFT, including more entries into and more distance travelled in the "anxiogenic" center zone of the OFT. It could be hypothesized based on the expression of Zscan10 in the embryonic brain that an impact on a pluripotent progenitor cell population for example in the limbic system could influence anxiety related behavior along the way of observations made in $D l x 1$ loss-of function mutants [60], where the $D l x 1$ sense $[60,61,62,63]$ and antisense transcript level is critical in progenitor fate decisions [15]. However, female Zscan10 homozygous mutants also show an increased acoustic startle response, which is not consistent with the notion of reduced anxiety, and demonstrated a functional visual impairment in the optokinetic drum test. It cannot be excluded that this visual impairment might have played a role in the observed OFT behavior of female Zscan10 homozygous mutants, since it could affect the perception of the arena and its center zone as anxiogenic. The increased urination observed in the neurology screen could however also be due to a renal dysfunction as indicated by the results from the clinical chemistry screen which revealed increased urea and creatinine levels as well was a slight hypocalcemia in males that among other causes can also be attributed to renal dysfunction.

Taken together, further neurological examinations and immunohistochemistry would be required to identify the exact nature of Zscan10 homozygous mutant behavior.

\section{Zscan10 remains expressed in potential progenitor cells of diverse organs}

All phenotypic findings were coherent with the embryonic and adult Zcan10 gene expression patterns established by SISH. Previous WISH expression patterns in midgestation embryos could have misinterpreted the punctate expression pattern of Zscan10 as background staining. We propose based on a more refined expression pattern by $\mathrm{SISH}$, the known interaction partners of Zscan10 [1] and the pleiotropic phenotype observed in Zscan 10 mutants, that Zscan 10 could play a role in regulating the availability of progenitor cells during mouse embryonic development and adulthood. In the case of Zscan 10 hypomorphic or loss-of-function mutations the number of progenitors might be reduced, either by a decrease in progenitor cell division or by premature terminal differentiation causing an overall reduction in cell mass of a variety of target tissues namely eye, heart, long bones and spleen. Identified grip strength, immunological and blood chemistry abnormalities could be downstream effects of the impact on progenitor cell populations in the affected organs. The pluripotency marker Sox 2 is coexpressed in many but not all of these organs, yet generally in fewer cells compared to Zscan10. This is not surprising as progenitor cells might have acquired a certain maturity and as such are no longer of pluripotent nature, yet can act as multipotent progenitors for cells at an advanced differentiation level. The exact mechanism by which Zscan 10 acts in a given progenitor cell population in vivo remains to be determined.

In summary, the observed eye phenotype in homozygous Zscan10 mutant mice supports previously proposed in vivo interactions between Sox2 and Zscan 10 based on earlier in vitro assays. The nature of the cellular expression pattern of Zscan 10 in midgestation embryos and adult organs and the changes in absolute weight of several organs as well as the composition of several cell populations in the homozygous mutants suggests a role for Zscan10 in maintaining a multipotent progenitor cell population or impacting on fate choice decisions thereof.

\section{Supporting Information}

Figure S1 Gene trap strategy. Illustrated is the pUPA-TRAP vector (not drawn to scale) as used by CMMR that was integrated into intron 1 upstream of the ATG start codon. Exons of the currently known five Zscan10 transcripts are drawn to scale as rectangular boxes, yellow and white representing coding and untranslated regions, respectively. The $270 \mathrm{bp}$ SISH probe (purple lines) is covering most of exon 3, all of exon 4 and part of exon 5 and is drawn to scale for transcript 1. Transcripts after insertion of the pUPA-TRAP vector before and after Cre-recombination are indicated. Generation of Zscan 10 protein after Cre-recombination is highly unlikely based on the design of the pUPA-TRAP vector. Transcription start site (TSS, black bend arrow), translation start (green arrow heads), translation stop (red arrow heads), splice acceptor site (SA), internal ribosome entry site (IRES), polyadenylation site (pA), RNA polymerase II promoter (RNAPII), recognition site for Cre recombinase (loxP), splice donor site (SD). Integration site of pUPA-TRAP vector is indicated by the blue arrow.

(EPS)

Figure S2 Results of the immunological screen. (A) Frequencies of leukocyte subpopulations during flow cytometry in peripheral blood after erythrocyte lysis [percentage of all leukocytes (CD45+ cells), or corresponding parent gate, respectively]. Means, standard deviation and p-values calculated by a linear model. (B) Levels of immunoglobulins ( $\mathrm{ug} / \mathrm{ml}$ ) in blood plasma. Medians, first and third quartile and p-values calculated by Wilcoxon rank-sum test. Missing measurements caused by Ig levels above and below measurability were replaced by $0.9 * \min /$ $1.1 *$ max of respective Ig measurement $(n=57)$. $(\mathrm{C})$ Total $\operatorname{IgE}$ in plasma were in normal range. Medians, first and third quartile and p-values calculated by a Wilcoxon rank-sum test.

(TIF)

Figure S3 Open Field Testing. Means, standard deviation and $\mathrm{p}$-values calculated by a linear model $(\mathrm{n}=60)$.

(TIF)

Figure S4 Organ weight. Medians, first and third quartile and $\mathrm{p}$-values calculated by a Wilcoxon rank-sum test $(\mathrm{n}=57)$.

(TIF)

Figure S5 Western blot of the homozygous Zscan10 mutant (-/ ) ESG line $L 2$ in comparison to wild type $(+/+)$ and heterozygous (+/ $)$ ESC. Using 15 ug each with the GIS206-Ab [1], maintained on mouse embryonic fibroblasts (MEF) or on MEF-free gelatinized plates (GEL) and aRB-HRP as loading control.

(EPS)

Figure S6 Sox $2, \mathrm{Hes} 5$ and EGFP expression in comparison to Zscan10. Sections through E15.5 (A-X) and E12.5 (Y-P') Zscan10-/- (G-R, $\left.\mathrm{K}^{\prime}-\mathrm{P}^{\prime}\right)$ and Zscan10+/- (A-F, S-J') mouse embryos showing expression of the transcription factors Hes 5 (AL), Zscan10 (S-D') and Sox2 ( $\left.\mathrm{E}^{\prime}-\mathrm{P}^{\prime}\right)$ as well as the pUPA reporter EGFP (M-R). Organs expressing the Notch pathway effector Hes 5 did not show any obvious difference in Hes 5 expression between Zscan10-/- and Zscan10+/- embryos as shown for the brain $(\mathrm{A}, \mathrm{G})$ neural tube (nt) $(\mathrm{B}, \mathrm{H})$ gut $(\mathrm{D}, \mathrm{J})$ and liver $(\mathrm{E}, \mathrm{K})$ with exception of the retinal layer $(\mathrm{C}, \mathrm{I})$, where the Hes 5 signal appeared 
less intense, either due to reduced expression levels or fewer cells expressing Hes 5 in the Zscan $10^{-1-}$ eye (I). Ectopic upregulation of Hes 5 in chondrogenic tissue was not observed (F,L). EGFP expression was similar to Zscan10 expression in all organs assayed for namely: Adrenal $(\mathrm{M}, \mathrm{S})$, kidney $(\mathrm{N}, \mathrm{T})$, heart $(\mathrm{O}, \mathrm{U})$, lung $(\mathrm{P}, \mathrm{V})$ vertebrae body and forming intervertebral disc (Q,W) and dorsal root ganglia (drg) (R,X). Sox2 was not detected in kidney and adrenal $\left(\mathrm{E}^{\prime}, \mathrm{K}^{\prime}\right)$, only faintly expressed in $n t$ and $\operatorname{drg}\left(\mathrm{G}^{\prime}, \mathrm{M}^{\prime}\right)$ but found coexpressed with Zscan 10 in the heart $\left(\mathrm{Z}, \mathrm{F}^{\prime}, \mathrm{L}^{\prime}\right)$, the apical ectodermal ridge (aer) $\left(\mathrm{C}^{\prime}, \mathrm{I}^{\prime}, \mathrm{O}^{\prime}\right)$ and the retina $\left(\mathrm{D}^{\prime}, \mathrm{J}^{\prime}, \mathrm{P}^{\prime}\right)$. (TIF)

Table S1 Genotyping results from offspring at weaning age $(\mathbf{n}=\mathbf{1 5 3})$. $\mathrm{P}$-value is calculated as one tailed probability values with $n=2$ degrees of freedom.

(EPS)

\section{Acknowledgments}

The authors are grateful to Felicia Huimei Hong for Western blot data on the Zscan10 lines, also Jie Wei Goh, Song Jie, Geraldine Leong, Valerie

\section{References}

1. Yu HB, Kunarso G, Hong FH, Stanton LW (2009) Zfp206, Oct4, and Sox2 are integrated components of a transcriptional regulatory network in embryonic stem cells. The Journal of biological chemistry 284: 31327-31335.

2. Liang Y, Huimei Hong F, Ganesan P, Jiang S, Jauch R, et al. (2012) Structural analysis and dimerization profile of the SCAN domain of the pluripotency factor Zfp206. Nucleic acids research 40: 8721-8732.

3. Zhang W, Morris QD, Chang R, Shai O, Bakowski MA, et al. (2004) The functional landscape of mouse gene expression. Journal of biology 3: 21.

4. Brandenberger R, Wei H, Zhang S, Lei S, Murage J, et al. (2004) Transcriptome characterization elucidates signaling networks that control human ES cell growth and differentiation. Nature biotechnology 22: 707-716.

5. Yoshikawa T, Piao Y, Zhong J, Matoba R, Carter MG, et al. (2006) Highthroughput screen for genes predominantly expressed in the ICM of mouse blastocysts by whole mount in situ hybridization. Gene expression patterns: GEP 6: 213-224.

6. Wang ZX, Kueh JL, Teh CH, Rossbach M, Lim L, et al. (2007) Zfp206 is a transcription factor that controls pluripotency of embryonic stem cells. Stem cells 25: 2173-2182.

7. Wang ZX, Teh CH, Kueh JL, Lufkin T, Robson P, et al. (2007) Oct4 and Sox2 directly regulate expression of another pluripotency transcription factor, Zfp206, in embryonic stem cells. The Journal of biological chemistry 282: 12822-12830.

8. Evans MJ, Kaufman MH (1981) Establishment in culture of pluripotential cells from mouse embryos. Nature 292: 154-156.

9. Martin GR (1981) Isolation of a pluripotent cell line from early mouse embryos cultured in medium conditioned by teratocarcinoma stem cells. Proceedings of the National Academy of Sciences of the United States of America 78: 7634 7638 .

10. Kraus P, Leong G, Tan V, Xing X, Goh JW, et al. (2010) A more cost effective and rapid high percentage germ-line transmitting chimeric mouse generation procedure via microinjection of 2-cell, 4-cell, and 8-cell embryos with ES and iPS cells. Genesis 48: 394-399.

11. Robledo RF, Rajan L, Li X, Lufkin T (2002) The Dlx5 and Dlx6 homeobox genes are essential for craniofacial, axial, and appendicular skeletal development. Genes \& development 16: 1089-1101.

12. Jung Y, Bauer G, Nolta JA (2012) Concise review: Induced pluripotent stem cellderived mesenchymal stem cells: progress toward safe clinical products. Stem cells 30: 42-47.

13. Lewandoski M, Wassarman KM, Martin GR (1997) Zp3-cre, a transgenic mouse line for the activation or inactivation of loxP-flanked target genes specifically in the female germ line. Current biology: CB 7: 148-151.

14. Kraus P, Xing X, Lim SL, Fun ME, Sivakamasundari V, et al. (2012) Mouse strain specific gene expression differences for illumina microarray expression profiling in embryos. BMC research notes 5: 232.

15. Kraus P, Sivakamasundari V, Lim SL, Xing X, Lipovich L, et al. (2013) Making sense of Dlx1 antisense RNA. Developmental biology 376: 224-235.

16. Tribioli C, Robledo RF, Lufkin T (2002) The murine fork head gene Foxn2 is expressed in craniofacial, limb, CNS and somitic tissues during embryogenesis. Mechanisms of Development 118: 161-163.

17. Gailus-Durner V, Fuchs H, Adler T, Aguilar Pimentel A, Becker L, et al. (2009) Systemic first-line phenotyping. Methods in molecular biology 530: 463-509.

18. Gailus-Durner V, Fuchs H, Becker L, Bolle I, Brielmeier M, et al. (2005) Introducing the German Mouse Clinic: open access platform for standardized phenotyping. Nature methods 2: 403-404.
Tan and all A*STAR BRC staff for their support. We would further like to thank Reinhard Seeliger, Jan Einicke, Michael Färberböck, Elfi Holupirek, Maria Kugler, Sören Kundt, Marja Ram, and Yvonne Sonntag, Bettina Sperling, Anja Wohlbier as well as the GMC animal caretaker team for expert technical assistance.

\section{Author Contributions}

Conceived and designed the experiments: PK SV HBY XX SLL TA JAAP LB AB LG WH SMH EJ KM CP OP BR JR JA RB DHB JG MK TK FN MO TS AOY OE EW WW HF VGD MH TL LWS. Performed the experiments: PK SV HBY XX SLL TA JAAP LB AB LG WH SMH EJ KM CP OP BR JR JA RB DHB JG MK TK FN MO TS AOY OE EW WW HF VGD MH TL LWS. Analyzed the data: PK SV HBY XX SLL TA JAAP LB AB LG WH SMH EJ KM CP OP BR JR JA RB DHB JG MK TK FN MO TS AOY OE EW WW HF VGD MH TL LWS. Contributed reagents/materials/analysis tools: PK SV HBY XX SLL TA JAAP LB AB LG WH SMH EJ KM CP OP BR JR JA RB DHB JG MK TK FN MO TS AOY OE EW WW HF VGD MH TL LWS. Contributed to the writing of the manuscript: PK SV HBY XX SLL TA JAAP LB AB LG WH SMH EJ KM CP OP BR JR JA RB DHB JG MK TK FN MO TS AOY OE EW WW HF VGD MH TL LWS.

19. Fuchs H, Gailus-Durner V, Adler T, Aguilar-Pimentel JA, Becker L, et al. (2011) Mouse phenotyping. Methods 53: 120-135.

20. Fuchs H, Schughart K, Wolf E, Balling R, Hrabe de Angelis M (2000) Screening for dysmorphological abnormalities - a powerful tool to isolate new mouse mutants. Mammalian genome: official journal of the International Mammalian Genome Society 11: 528-530.

21. Puk O, Dalke C, Favor J, de Angelis MH, Graw J (2006) Variations of eye size parameters among different strains of mice. Mammalian genome: official journal of the International Mammalian Genome Society 17: 851-857.

22. Prusky GT, Alam NM, Beekman S, Douglas RM (2004) Rapid quantification of adult and developing mouse spatial vision using a virtual optomotor system. Investigative ophthalmology \& visual science 45: 4611-4616.

23. Mandillo S, Tucci V, Holter SM, Meziane H, Banchaabouchi MA, et al. (2008) Reliability, robustness, and reproducibility in mouse behavioral phenotyping: a cross-laboratory study. Physiological genomics 34: 243-255.

24. Hoelter SM, Glasl L (2011) High throughput mouse phenotyping. Neuromethods 61: 109-133.

25. Rathkolb B, Hans W, Prehn C, Fuchs H, Gailus-Durner V, et al. (2013) Clinical Chemistry and Other Laboratory Tests on Mouse Plasma or Serum. Curr Protoc Mouse Biol 3: 69-100.

26. Neff F, Flores-Dominguez D, Ryan DP, Horsch M, Schroder S, et al. (2013) Rapamycin extends murine lifespan but has limited effects on aging. The Journal of clinical investigation 123: 3272-3291.

27. Akazawa C, Sasai Y, Nakanishi S, Kageyama R (1992) Molecular characterization of a rat negative regulator with a basic helix-loop-helix structure predominantly expressed in the developing nervous system. The Journal of biological chemistry 267: 21879-21885.

28. Kageyama R, Nakanishi S (1997) Helix-loop-helix factors in growth and differentiation of the vertebrate nervous system. Current opinion in genetics \& development 7: 659-665.

29. Hojo M, Ohtsuka T, Hashimoto N, Gradwohl G, Guillemot F, et al. (2000) Glial cell fate specification modulated by the bHLH gene Hes 5 in mouse retina. Development 127: 2515-2522.

30. Niwa H, Miyazaki J, Smith AG (2000) Quantitative expression of Oct-3/4 defines differentiation, dedifferentiation or self-renewal of ES cells. Nature genetics 24: 372-376.

31. Nichols J, Zevnik B, Anastassiadis K, Niwa H, Klewe-Nebenius D, et al. (1998) Formation of pluripotent stem cells in the mammalian embryo depends on the POU transcription factor Oct4. Cell 95: 379-391.

32. Kehler J, Tolkunova E, Koschorz B, Pesce M, Gentile L, et al. (2004) Oct4 is required for primordial germ cell survival. EMBO reports 5: 1078-1083.

33. Hochedlinger K, Yamada Y, Beard C, Jaenisch R (2005) Ectopic expression of Oct-4 blocks progenitor-cell differentiation and causes dysplasia in epithelial tissues. Cell 121: 465-477.

34. Hever AM, Williamson KA, van Heyningen V (2006) Developmental malformations of the eye: the role of PAX6, SOX2 and OTX2. Clinical genetics 69: 459-470.

35. Kelberman D, de Castro SC, Huang S, Crolla JA, Palmer R, et al. (2008) SOX2 plays a critical role in the pituitary, forebrain, and eye during human embryonic development. The Journal of clinical endocrinology and metabolism 93: 18651873.

36. Halder G, Callaerts P, Gehring WJ (1995) Induction of ectopic eyes by targeted expression of the eyeless gene in Drosophila. Science 267: 1788-1792. 
37. Hill RE, Favor J, Hogan BL, Ton CC, Saunders GF, et al. (1991) Mouse small eye results from mutations in a paired-like homeobox-containing gene. Nature 354: 522-525.

38. Puk O, Yan X, Sabrautzki S, Fuchs H, Gailus-Durner V, et al. (2013) Novel small-eye allele in paired box gene 6 (Pax6) is caused by a point mutation in intron 7 and creates a new exon. Molecular vision 19: 877-884.

39. Osumi N, Shinohara H, Numayama-Tsuruta K, Maekawa M (2008) Concise review: Pax6 transcription factor contributes to both embryonic and adult neurogenesis as a multifunctional regulator. Stem cells 26: 1663-1672.

40. Dames P, Puff R, Weise M, Parhofer KG, Goke B, et al. (2010) Relative roles of the different Pax6 domains for pancreatic alpha cell development. BMC developmental biology 10: 39 .

41. Brendolan A, Rosado MM, Carsetti R, Selleri L, Dear TN (2007) Development and function of the mammalian spleen. BioEssays: news and reviews in molecular, cellular and developmental biology 29: 166-177.

42. Fantes J, Ragge NK, Lynch SA, McGill NI, Collin JR, et al. (2003) Mutations in SOX2 cause anophthalmia. Nature genetics 33: 461-463.

43. Ragge NK, Lorenz B, Schneider A, Bushby K, de Sanctis L, et al. (2005) SOX2 anophthalmia syndrome. American journal of medical genetics Part A 135: 1-7; discussion 8.

44. Hagstrom SA, Pauer GJ, Reid J, Simpson E, Crowe S, et al. (2005) SOX2 mutation causes anophthalmia, hearing loss, and brain anomalies. American journal of medical genetics Part A 138A: 95-98.

45. Ragge NK, Brown AG, Poloschek CM, Lorenz B, Henderson RA, et al. (2005) Heterozygous mutations of OTX2 cause severe ocular malformations. American journal of human genetics 76: 1008-1022.

46. Zenteno JC, Gascon-Guzman G, Tovilla-Canales JL (2005) Bilateral anophthalmia and brain malformations caused by a 20-bp deletion in the SOX2 gene. Clinical genetics 68: 564-566.

47. Wang B, Lufkin T, Rubenstein JL (2011) Dlx6 regulates molecular properties of the striatum and central nucleus of the amygdala. The Journal of Comparative Neurology 519: 2320-2334.

48. Taranova OV, Magness ST, Fagan BM, Wu Y, Surzenko N, et al. (2006) SOX2 is a dose-dependent regulator of retinal neural progenitor competence. Genes \& development 20: 1187-1202.

49. Matsushima D, Heavner W, Pevny LH (2011) Combinatorial regulation of optic cup progenitor cell fate by SOX2 and PAX6. Development 138: 443-454.
50. van der Loo B, Martin JF (1999) A role for changes in platelet production in the cause of acute coronary syndromes. Arteriosclerosis, thrombosis, and vascular biology 19: 672-679.

51. Thon JN, Italiano JE, Jr. (2012) Does size matter in platelet production? Blood 120: 1552-1561.

52. Chu SG, Becker RC, Berger PB, Bhatt DL, Eikelboom JW, et al. (2010) Mean platelet volume as a predictor of cardiovascular risk: a systematic review and meta-analysis. Journal of thrombosis and haemostasis: JTH 8: 148-156.

53. Watala C, Boncler M, Gresner P (2005) Blood platelet abnormalities and pharmacological modulation of platelet reactivity in patients with diabetes mellitus. Pharmacological reports: PR 57 Suppl: 42-58.

54. Gieger C, Radhakrishnan A, Cvejic A, Tang W, Porcu E, et al. (2011) New gene functions in megakaryopoiesis and platelet formation. Nature 480: 201-208.

55. Hall CS (1934) Emotional behavior in the rat. I. Defecation and urination as measures of individual differences in emotionality. Journal of Comparative Psychology 18: 385-403.

56. Malisch JL, Saltzman W, Gomes FR, Rezende EL, Jeske DR, et al. (2007) Baseline and stress-induced plasma corticosterone concentrations of mice selectively bred for high voluntary wheel running. Physiological and biochemical zoology: PBZ 80: 146-156.

57. Jacobson L (2005) Hypothalamic-pituitary-adrenocortical axis regulation. Endocrinol Metab Clin North Am 34: 271-292, vii.

58. Geyer MA (1999) Assessing prepulse inhibition of startle in wild-type and knockout mice. Psychopharmacology 147: 11-13.

59. Madsen GF, Bilenberg N, Cantio C, Oranje B (2013) Increased Prepulse Inhibition and Sensitization of the Startle Reflex in Autistic Children. Autism research: official journal of the International Society for Autism Research.

60. Mao R, Page DT, Merzlyak I, Kim C, Tecott LH, et al (2009) Reduced conditioned fear response in mice that lack Dlx 1 and show subtype-specific loss of interneurons. Journal of neurodevelopmental disorders 1: 224-236.

61. Cobos I, Calcagnotto ME, Vilaythong AJ, Thwin MT, Noebels JL, et al. (2005) Mice lacking Dlx 1 show subtype-specific loss of interneurons, reduced inhibition and epilepsy. Nature neuroscience 8: 1059-1068.

62. Jones DL, Howard MA, Stanco A, Rubenstein JL, Baraban SC (2011) Deletion of Dlx1 results in reduced glutamatergic input to hippocampal interneurons. Journal of neurophysiology 105: 1984-1991.

63. Petryniak MA, Potter GB, Rowitch DH, Rubenstein JL (2007) Dlx1 and Dlx2 control neuronal versus oligodendroglial cell fate acquisition in the developing forebrain. Neuron 55: 417-433. 